\title{
DAMAGE EVOLUTION IN DYNAMIC DEFORMATION OF SILICON CARBIDE
}

\author{
C. J. SHIH $\dagger^{\dagger}$, M. A. MEYERS ${ }^{\dagger}+$, V. F. NESTERENKO ${ }^{1}$ and S. J. CHEN $^{2}$ \\ ${ }^{1}$ Department of Mechanical and Aerospace Engineering, University of California, San Diego, La Jolla, \\ CA 92093, USA and ${ }^{2}$ National Center for Electron Microscopy, Lawrence Berkeley National \\ Laboratory, Berkeley, CA 94720, USA
}

(Received 9 March 1998; accepted 29 October 1999)

\begin{abstract}
Damage evolution was investigated in silicon carbide by subjecting it to dynamic deformation in (a) a compression Hopkinson-Kolsky bar (compressive stresses of $5 \mathrm{GPa}$ ), and (b) high-velocity impact under confinement (compressive stresses of 19-32 GPa) by a cylindrical (rod) tungsten alloy projectile. Considerable evidence of plastic deformation, as dislocations and stacking faults, was found in the fractured specimens. A polytype transformation was observed through a significant increase in the $6 \mathrm{H}-\mathrm{SiC}$ phase at compressive stresses higher than $4.5 \mathrm{GPa}$ (in the vicinity of the dynamic compressive failure strength). Profuse dislocation activity was evident in the frontal layer in the specimen recovered from the projectile impact. The formation of this frontal layer is proposed to be related to the high lateral confinement, imposed by the surrounding material. It is shown that plastic deformation is consistent with an analysis based on a ductility parameter $\left(\Delta=K_{\mathrm{C}} / \tau_{y} \sqrt{\pi c}\right)$. The microstructural defects and their evolution were found to be dependent on the concentration of boron and aluminum, which were added as sintering aids. Several mechanisms are considered for the initiation of fracture: (a) dilatant cracks induced by mismatch in the effective elastic moduli between two adjacent grains, leading to internal tensile stresses and creating transgranular fracture. Finite element calculations show that high tensile stresses are generated due to elastic compatibility strains; (b) Zener-Stroh cracks nucleated by the piled up dislocations along grain boundaries, and resulting in intergranular fracture; (c) cracks due to existing flaws connected with grain-boundary phases, voids, etc.; and (d) stress concentrations due to twinning and stacking faults. The high dislocation density observed in the impacted specimen is consistent with existing models of microplasticity. (C) 2000 Acta Metallurgica Inc. Published by Elsevier Science Ltd. All rights reserved.
\end{abstract}

Keywords: Carbides; Mechanical properties; Dynamic phenomena; Transmission electron microscopy (TEM)

\section{INTRODUCTION}

In ceramics, high homologous temperatures are usually required for plastic deformation; the intrinsic resistance to dislocation motion makes them brittle. At ambient temperature, failure is most often initiated by crack propagation. The failure strength of ceramics is strongly dependent on the stress state, and lateral confinement plays a major role in damage evolution. The effect of lateral confinement has been recognized as early as 1924 by Griffth [1] and was incorporated into a failure criterion. It was modified by McClintock and Walsh [2] to include the effect of friction of crack surfaces. Castaing et al. [3] demonstrated that, under superimposed hydrostatic stresses, $\mathrm{Al}_{2} \mathrm{O}_{3}$ can undergo

\footnotetext{
$\dagger$ Present address: Ceradyne, Costa Mesa, CA 92626, USA

$\$$ To whom all correspondence should be addressed.
}

significant plastic deformation by dislocation motion at ambient temperature. Mitchell, Pletka, Heuer and co-workers [4-6] developed a work-hardening theory for $\mathrm{Al}_{2} \mathrm{O}_{3}$, based on the interaction of prismatic dislocation loops with gliding dislocations. They incorporated the effect of impurities as solid solution strengthening. In shock-wave propagation, a fully confined stress configuration is generated (uniaxial strain state) and the Hugoniot elastic limit (HEL) is usually observed in the range of 10-25 GPa. There has been considerable debate as to the nature of Hugoniot elastic limit; it has been interpreted as either the onset of fracture (comminution) or the beginning of plastic deformation. In high-strain-rate deformation, there is a proposal by Lankford [7] that fracture in $\mathrm{Al}_{2} \mathrm{O}_{3}$ specimens tested in unconfined (uni-axial stress) conditions at $10^{3} \mathrm{~s}^{-1}$ was initiated by plastic deformation (deformation twins). Results by Hoke et al. [8] on $\mathrm{TiB}_{2}$ seem to confirm that plastic defor- 
mation plays a role in the initiation of failure under dynamic loading. Chen and Ravichandran [9] investigated the dynamic response of AIN under various degrees of lateral confinement and have obtained a considerable dependence of failure stress on the lateral stress. They have also suggested that plastic deformation plays a role in failure. Louro and Meyers [10] found a considerable amount of dislocation in alumina subjected to impact loading at pressures in the range of $5 \mathrm{GPa}$. Espinosa [11] and Espinosa et al. [12], using both normal and inclined impact experiments in high-purity alumina and VISTAL $\left(\mathrm{Al}_{2} \mathrm{O}_{3}\right.$-glass), found some dislocation activity, but did not attribute too much importance to it. The plastic flow of intergranular glassy regions was considered as the principal mechanism of damage initiation.

In order to elucidate the micromechanical processes responsible for the initiation of dynamic failure in silicon carbide, two testing methods, providing different stress states, were used: (a) dynamic compression testing under unconfined, uniaxial stress (split Hopkinson-Kolsky bar) and (b) dynamic compression under full confinement provided by conditions under impact with long rod penetrator. Two hot-pressed silicon carbides, representing the two most important additive families (B-doped and Al-doped SiC) were studied. The choice of $\mathrm{SiC}$ is based on its excellent ballistic properties, which are the consequence of low density, high hardness, and high Young's modulus.

\section{MATERIAL AND EXPERIMENTAL PROCEDURES}

Two different silicon carbides (designated by SiC-I and $\mathrm{SiC}$-II) were investigated in this study. Standard hot pressing procedures were used to fabricate these materials where $\alpha$-SiC powder was first mixed with sintering aids [13]. The blended powder was loaded into a graphite die and then hot pressed above $2000^{\circ} \mathrm{C}$ at $18 \mathrm{MPa}$ under a controlled atmosphere. SiC-I is a conventional $\mathrm{SiC}$, using boron and carbon as sintering aids. The carbon removes the oxide layer which inhibits the densification [13]. Boron, the main addition in SiC-I, is believed to create atomic vacancies to promote grain-boundary diffusion [14-16] and enhances the sintering kinetics. SiC-II, using an Al-based compound as the sintering aid, is a ballistic grade $\mathrm{SiC}$, commercially sold as CERCOM SiC-B.

The fracture toughness was obtained using the Chevron-Notch four-point bending test [17]. The flexural strength was measured using the procedures outlined in ASTM C-1161 (four-point-bending, using the type-B configuration), and the probability of failure was calculated from the flexural strength data, using Weibull statistics [18]. Elastic properties, longitudinal speed $\left(V_{\mathrm{L}}\right)$, and shear speed $\left(V_{\mathrm{S}}\right)$ were measured using the ultrasonic technique. The density of hot-pressed $\mathrm{SiC}$ was determined using the water absorption method (ASTM C-373). Hardness was measured using Knoop micro-hardness technique at $300 \mathrm{gf}$ of loading (ASTM C-1326). Average grain size was calculated by an intercept method (ASTM E-112) on etched surfaces, using Murakami's reagent.

The conventional split Hopkinson-Kolsky pressure bars were originally designed to characterize the plastic deformation of metals at high strain rates. To accurately investigate the deformation of ceramics, the following modifications were applied: (1) a pulse shaper placed in front of the incident bar to ensure uniform stress [19], (2) a momentum trap to allow the specimen to undergo single loading [20], (3) a strain gage on the specimen to accurately measure the strain in the specimen [21], and (4) a pair of contact platens sandwiching the ceramic specimen to prevent damage in the steel bars while the specimen was catastrophically fractured $[9,21]$. SiC whisker-reinforced $\mathrm{Si}_{3} \mathrm{~N}_{4}$ composite (commercially sold as CERCOM CIW15) was selected for the contact platens, because of its high strength (900 MPa flexural strength) and fracture toughness (8 $\mathrm{MPa} \sqrt{\mathrm{m}})$. The cross-section of the contact platens was machined so that their geometry impedance ( $\rho \mathrm{CA}$, where $\rho$ is the density, $C$ is the longitudinal velocity, and $A$ is the cross-section) matched the geometry impedance of the steel bars. This elastic pulse deforms the $\mathrm{SiC}$ specimen in a uniaxial stress condition in the absence of lateral confinement. SiC was dynamically stressed using the modified split Hopkinson bar at a strain rate between 400 and $800 \mathrm{~s}^{-1}$.

In real armor applications, material inertia and compressive stresses induced by the bending of the structure impose a lateral confinement, and the strain rate is higher than the strain rate achieved in the split Hopkinson-Kolsky bar test. Recently, Hauver et al. [22-25] developed a testing method to defeat the long rod projectile at a high velocity $(1.5 \mathrm{~km} / \mathrm{s})$, in front of the ceramic target. A shockwave attenuator was placed in front of the ceramic target to reduce the shock-wave damage in the ceramic. The ceramic was confined through a shrink-fit metal casing, and the confinement pressure was a few hundred MPa. Interface coupling was applied on the ceramic front face to allow the plastic deformation and flow of the penetrator. This type of testing configuration allowed the recovery of the impacted specimens for further microstructural characterization.

\section{RESULTS AND DISCUSSION}

\subsection{Quasi-static properties of hot-pressed SiC}

SiC-I had a slightly lower density (3.18 vs 3.21 ) and a slightly larger average grain size (5.8 vs $4.1 \mu \mathrm{m})$ than SiC-II. SiC-I also had a slightly lower Young's modulus (436 vs $446 \mathrm{GPa}$ ), because of the 
porosity. Nevertheless, the porosity in both $\mathrm{SiC}$ was $<1 \%$. SiC-I had a lower flexural strength (380 vs $542 \mathrm{GPa}$ ) and Weibull modulus (5.9 vs 10.9) than $\mathrm{SiC}-\mathrm{II}$, and the probability of failure of these two $\mathrm{SiC}$ is graphically shown in Fig. 1. Strength-limiting flaws with sizes as large as $100 \mu \mathrm{m}$ were found in $\mathrm{SiC}$-I. In contrast, similar strength-limiting flaws for SiC-II were not found. This is consistent with the higher flexural strength and Weibull modulus exhibited by SiC-II.

SiC-I exhibits transgranular fracture, while SiC-II shows intergranular fracture. It has been commonly assumed that the fracture energy of the grain boundary is lower than the energy of single-crystal cleavage planes. This assumption has been used for qualitative explanations of the occurrence of intergranular vs transgranular fracture. However, Rice $[26,27]$ pointed out that the determination of fracture mode is much more complicated. First, there are greater surface areas involved in intergranular fracture than in transgranular fracture, and the overall energy for intergranular fracture may be higher than the energy for transgranular fracture. Second, the intergranular fracture exhibits a complicated mixed-mode loading (Mode I and II) on the individual fracture facets. It is believed that the fracture mode influences the macroscopic fracture behavior. SiC-I failed by transgranular fracture, exhibiting a lower fracture toughness $(2.5 \mathrm{MPa} \sqrt{\mathrm{m}})$; SiC-II failed by intergranular fracture, showing a higher fracture toughness $(4.1 \mathrm{MPa} \sqrt{\mathrm{m}})$. It is thought that the ceramic with the intergranular fracture characteristics has a higher toughness, because of crack deflection toughening.

\subsection{Dynamic deformation of SiC under uniaxial stress}

3.2.1. Dynamic fracture of SiC. Lankford [28, 29] demonstrated a strain rate dependence of compressive strength for several ceramics, including $\mathrm{SiC}$ : the compressive strength increases with strain rate. The current results are shown, together with Lankford's

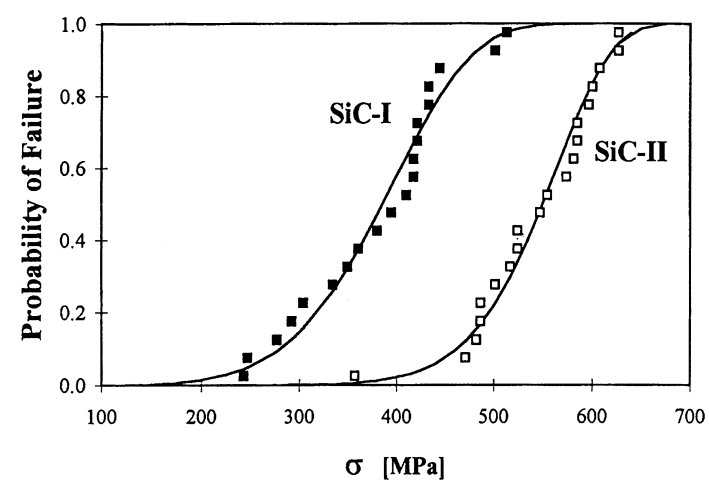

Fig. 1. Probability of failure: experimental results (squares) and Weibull statistics (continuous curves). results, in Fig. 2(a). The $\mathrm{SiC}$ used in Lankford's study was a sintered $\mathrm{SiC}$ (made by Carborundum Corporation) using boron-based additives and is similar to SiC-I. Both SiC-I and SiC-II had compressive strengths comparable to Lankford's sintered $\mathrm{SiC}$ in the strain rate range between 400 and $800 \mathrm{~s}^{-1}$ : the average compressive strengths of SiC-I and $\mathrm{SiC}-\mathrm{II}$ are 4.7 and $5.1 \mathrm{GPa}$, respectively. However, the average quasistatic compressive strengths of SiC-I and SiC-II were 4.8 and $5.4 \mathrm{GPa}$, respectively. These values are significantly higher than Lankford's data (4.0 GPa). Great care was taken in specimen preparation, both for quasistatic and dynamic tests. Specimens were polished to a mirror finish, and the parallelism of the compressive surfaces was controlled to within $5 \mu \mathrm{m}$. It was found that the alignment of the loading is crucial in compressive testing. During quasistatic testing, in addition to the self-aligned compressive fixture, two steel foils $(25 \mu \mathrm{m}$ thick $)$ were placed on the compressive surfaces to ensure the alignment of the applied force. The shape of the specimens is also important. Under quasistatic loading, the parallelepiped-shaped specimens (with the dimension of $4 \times$ $4 \times 8 \mathrm{~mm}$ ) had average compressive strengths of 4.3 and $4.9 \mathrm{GPa}$, for $\mathrm{SiC}-\mathrm{I}$ and $\mathrm{SiC}-\mathrm{II}$, respectively, which were about $0.5 \mathrm{GPa}$ lower than the cylindrical specimens, because of stress concentration on the edges. As shown in Fig. 2(a), the strain rate effect, reported by Lankford [28, 29], activates when the strain rates are higher than $10^{3} \mathrm{~s}^{-1}$; the current testing configuration could only achieve strain rates up to $800 \mathrm{~s}^{-1}$. In our modified split Hopkinson bar testing, a pulse shaper was placed in front of the incident bar to ensure a uniform stress. The plastic deformation of the pulse shaper increased the rise time during loading, but also reduced the strain rate of the ceramic specimen. To evaluate the strain rate effects, a Hopkinson bar with a smaller bar diameter have to be used to achieve higher strain rates. It is easy to interpret the "overshoot" occurring before stress equilibration as an increase in strength, and this might have contributed to the larger strength values. The increase in compressive strength of ceramics, at strain rates on the order of $10^{3} \mathrm{~s}^{-1}$ and higher, has been analytically predicted by Nemat-Nasser and Deng [30], using interacting cracks, and Ravichandran and Subhash [31], using non-interacting cracks. Ravichandran and Subhash $[31,32]$ proposed an expression for the critical strain rate at which the strength becomes significantly strain-rate dependent. From elasticity:

$$
\sigma_{\mathrm{c}}=E \varepsilon=E \dot{\varepsilon} t_{\mathrm{c}}
$$

where $\sigma_{\mathrm{c}}$ is the compressive strength, $t_{\mathrm{c}}$ is the time to propagate a crack along entire specimen, and $\dot{\varepsilon}$ is the strain rate. This time is equal to the characteristic length divided by the crack propagation velocity, $C^{*}$. Since failure occurs by axial splitting, the 
characteristic length is equal to the specimen length, $l_{\mathrm{S}}$. Thus, the critical strain rate, $\dot{\varepsilon}^{*}$, is:

$$
\dot{\varepsilon}^{*}=\frac{\sigma_{\mathrm{c}} C^{*}}{E l_{\mathrm{S}}} .
$$

Assuming that the crack propagation velocity, $C^{*}$, is equal to $0.2 C_{\mathrm{S}}$, where $C_{\mathrm{S}}$ is the shear wave velocity, one obtains: $\varepsilon^{*} \approx 2 \times 10^{3} s^{-1}\left(\sigma_{c}=5 \mathrm{GPa} ; E=\right.$ $\left.440 \mathrm{GPa} ; l_{\mathrm{S}}=7.6 \mathrm{~mm} ; C_{\mathrm{S}}=7600 \mathrm{~m} / \mathrm{s}\right)$. This is slightly above the strain rate used in the Hopkinson bar in the current experiments (400-800 $\mathrm{s}^{-1}$ ) and explains the virtual absence in strain-rate dependence observed.

Fragments were collected after high-strain-rate testing, and their size was estimated using optical microscopy. As shown in Fig. 2b, SiC-II had larger fragments than SiC-I. Grady [33] proposed an analytical model, based on the balance between the kinetic energy and the newly created surface energy, to predict the fragment size:

$$
d=\left(\frac{\sqrt{20} K_{\mathrm{IC}}}{\rho C \dot{\varepsilon}}\right)^{2 / 3}
$$

where $d$ is the fragment size, $K_{\mathrm{IC}}$ is the fracture toughness, $\rho$ is the density, $C$ is the sonic velocity and $\dot{\varepsilon}$ is the strain rate. This equation shows that the fragment size increases with the material resist-

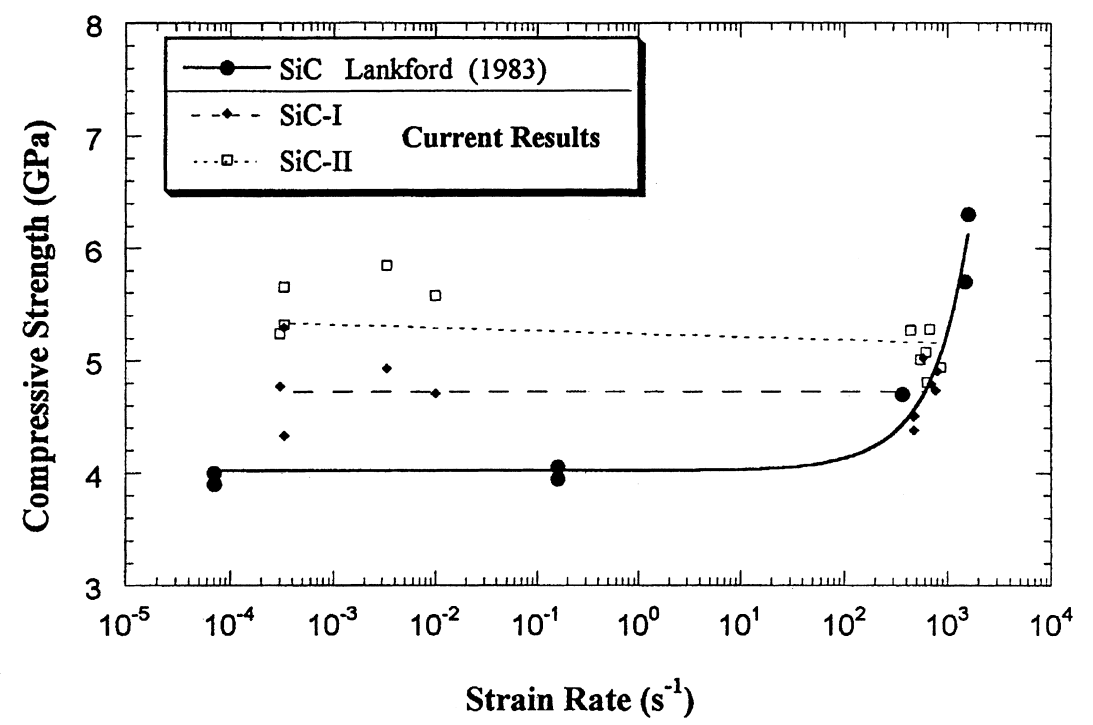

(a)

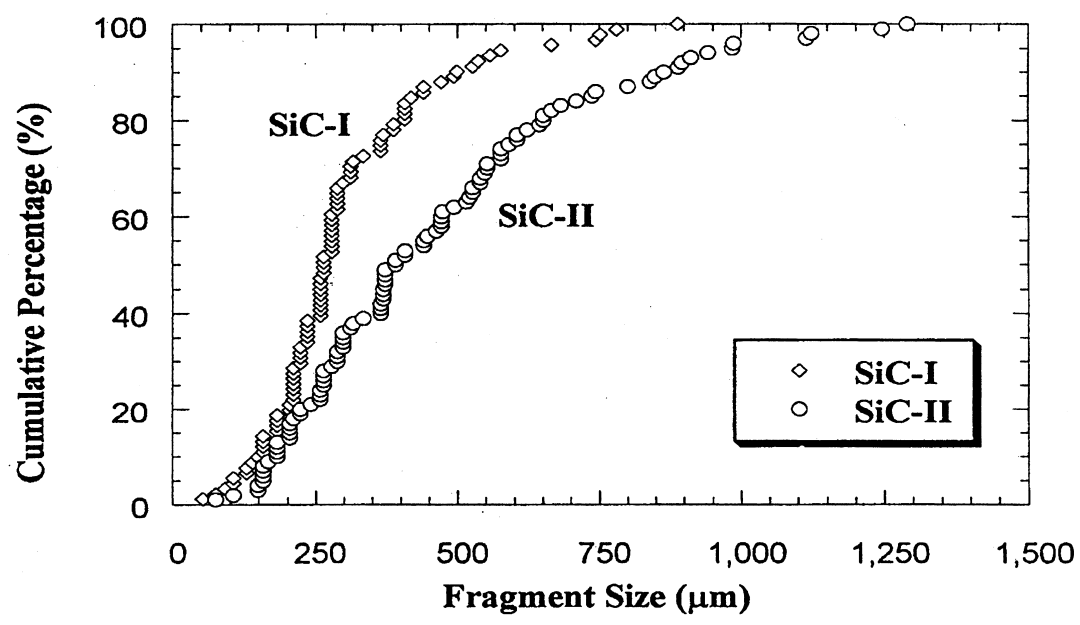

(b)

Fig. 2. (a) Compressive strength of $\mathrm{SiC}$ under high strain rates (individual test results marked by symbols). (b) Cumulative fragment size distribution. 
ance to cracking $\left(K_{\mathrm{IC}}\right)$. SiC-II had a higher fracture toughness, and a concomitantly larger fragment size than SiC-I, in accordance with equation (3). However, as shown in Fig. 3(a), the predicted fragment size is about one order of magnitude larger than the measured fragment size. The Grady model is only based on the balance of the local kinetic energy and the energy to generate surfaces of the fragments. The fragment size is obtained from the minimum of the energy, $E$. This energy can be expressed as the sum of the fracture energy $(\Gamma)$ and the local kinetic energy of the fragments $T$ (this is the kinetic energy within fragments). Thus, the total energy, $E_{1}$, is

$$
E_{1}=T+\Gamma \text {. }
$$

This total energy, $E_{1}$, is provided by the dynamic event preceding fragmentation. By taking $\frac{\mathrm{d} E 1}{\mathrm{~d} r}=0$ and making appropriate substitutions arrives at equation (3). In Fig. 3(b), the minimum gives $d_{\mathrm{G}}$. If additional work terms are involved in the energy balance, the predicted fragment size would be different than the size calculated from equation (3). Two terms should be added to the energy $E$ : a plastic work term $(W)$ and an internal damage term $(D)$. The term $W$ represents the contribution due to dislocations, stacking faults, and polytypes. The term $D$ represents cracks within the fragments. Thus, the total energy is:

$$
E_{2}=T+\Gamma+W+D
$$

It is assumed that the energy, $E$, available prior to fragmentation and damage is constant (and dictated by the strain rate). Thus, $E_{1}=E_{2}$. This is a more

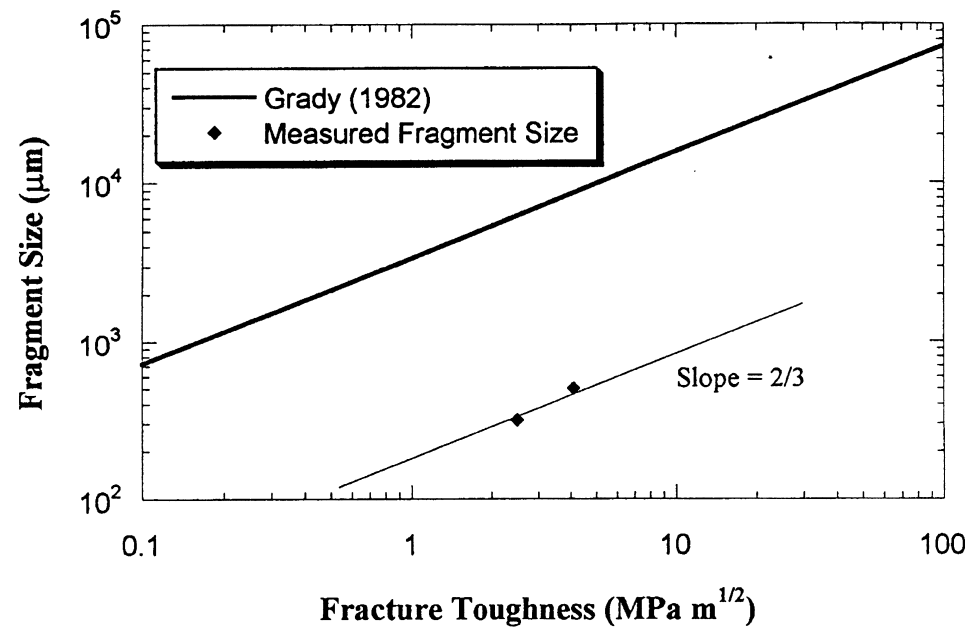

(a)

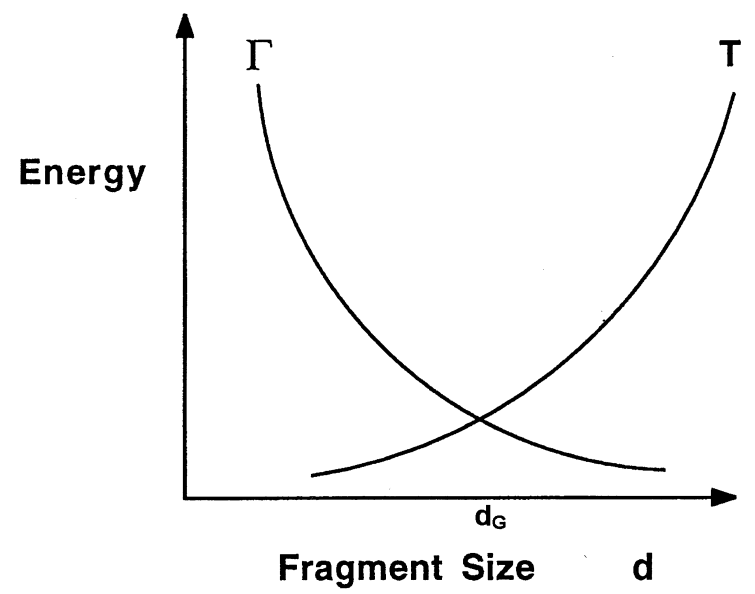

(b)

Fig. 3. (a) Fragment size as a function of fracture toughness. (b) Schematic representation of Grady theory and its modification by incorporating internal damage and deformation work terms. 
realistic configuration than the original proposal and can, if quantified, predict the correct fragment size. The microplasticity term can be estimated from the residual defect density (dislocations and stacking faults). A simplified expression is $W=\rho \mathrm{Gb}^{2}$ (where $\rho$ is the dislocation density, $b$ is the Burgers vector, and $G$ is the shear modulus). Assuming $\rho=10^{14} \mathrm{~m}^{-2}, b=0.5 \mathrm{~nm}$, and $G=186$ GPa, one obtains: $W=46.5 \times 10^{5} \mathrm{~J} / \mathrm{m}^{3}$. The internal damage is due to cracks that only propagate partially through the fragments. Aimone et al. [34] (see also Meyers [35], pp. 576-578) showed that, in shock-loaded quartz monzonite, the total surface energy generated is higher, by a factor between 50 and 100 , than the surface energy due to the fragments (between 20 and $200 \mathrm{~mm}$ in quartz monzonite). It is also possible to make a first-order estimate of $\Gamma$. Taking the surface energy as $1 \mathrm{~J} / \mathrm{m}^{2}$, the particle size/surface area relationship as $d A=6$, and a particle size $d=250 \mu \mathrm{m}$, one obtains: $\Gamma=$ $2.4 \times 10^{4} \mathrm{~J} / \mathrm{m}^{3}$. Thus, $W$ is one order of magnitude larger than $\Gamma$; the internal damage term, $D$, can be orders of magnitude higher than $\Gamma$. It is concluded that, in the current results, microplasticity and the internal damage of fragments play a significant role.

The fracture surfaces of the fragments were also examined using SEM. SiC-I failed by transgranular fracture, and SiC-II failed by intergranular fracture. These fracture modes under high-strain-rate deformation are identical to the fracture modes under quasistatic bending. It is concluded that the interaction between cracks and the microstructure is independent of strain rate in the investigated regions. Brokenbough et al. [36] and Suresh et al. [37] observed, nevertheless, an increase in fracture toughness with strain rate in ceramics $\left(K_{\mathrm{ID}} / K_{\mathrm{IC}}=\right.$ 1.1-1.4).

Some monolithic ceramics (such as $\mathrm{Al}_{2} \mathrm{O}_{3}$ and $\mathrm{Si}_{3} \mathrm{~N}_{4}$ ) contain intergranular glassy phases. The glassy phase can significantly influence the properties of the ceramic. For example, Cagnoux and Longy [38] have demonstrated that the dynamic deformation of $\mathrm{Al}_{2} \mathrm{O}_{3}$ containing a high amount $(10 \%)$ of glassy phase is accomplished by the microcracking of the intergranular glassy phase. On the contrary the deformation of pure $\mathrm{Al}_{2} \mathrm{O}_{3}$ is carried out by the microplasticity of $\mathrm{Al}_{2} \mathrm{O}_{3}$ grains, through the generation and movement of dislocations. Yeshurun et al. [39] studied the $\mathrm{Al}_{2} \mathrm{O}_{3}$ with a glassy phase, and proposed that the impedance mismatch is the primary factor for the microstructural damage in the phase boundaries. The microcracking in the intergranular glassy phase leads to local residual stress concentration and local heating, through dislocation multiplication and glide, as well as flow and crystallization of the glass [39]. Espinosa [11] studied VISTAL, an alumina-based ceramic containing an intergranular glassy phase, and attributed a considerable importance to plastic deformation of the glassy phase. Louro [40] observed very interesting features in the glassy phase that indicate viscous flow during impact (Fig. 69 from [40]). Glassy ligaments between $\mathrm{Al}_{2} \mathrm{O}_{3}$ particles were considered as evidence of viscous flow. Earlier reports by Yeshurun et al. [39] indicate the same effect.

The high-resolution electron micrographs of grain boundaries [Figs 4(a) and (b)] for SiC-I and SiC-II show extended regions without intergranular phases. The difference in the fracture modes between these $\mathrm{SiC}$ cannot be explained using the models derived from the glassy intergranular phases. However, in some isolated regions secondphase particles can be seen [see Fig. 4(c)]. The highresolution TEM micrographs of Figs 4(a) and (b) show that if there are impurities along the grain boundaries, they are on a scale escaping detection. The banding of the structure, indicative of stacking faults and polytypes, is clearly seen.

3.2.2. Dynamic deformation, prior to the catastrophic failure. Several specimens were loaded below their failure strength to explore the damage evolution during application of compressive traction. Longitudinal sonic velocity, along the loading axis of the recovered specimens, was measured using the ultrasonic technique. Results indicated that there was no degradation in the sonic velocity, even for the specimens stressed up to $95 \%$ of failure. Nucleation and growth of microcracks have been proposed to cause the compressive failure of brittle materials [29, 30]. The absence of the sonic velocity degradation in this study may be attributed to: (a) the possible alignment of the microcracks along the loading axis (that cannot be detected by the test configuration used), and (b) the low density of the microcracks. In the absence of lateral confinement, the microcracks tend to align along the principal loading direction $[41,42]$.

$\mathrm{SiC}$ crystals consist of layers of close-packed atoms, and the difference between various polytypes is only in their stacking sequence. Numerous polytypes have been observed in $\mathrm{SiC}$ [43]. Although $\mathrm{SiC}$ can theoretically have an infinite number of polytypes, $2 \mathrm{H}, 3 \mathrm{C}, 4 \mathrm{H}, 6 \mathrm{H}$ and $15 \mathrm{R}-\mathrm{SiC}$ are the most commonly seen polytypes. The polytype transformation is influenced by the thermal stability, impurity and gas environment [44]. Periodic slip and layer displacement have been proposed for the polytype transformation [44] (Fig. 5).

Tanaka and Iyi [45] developed an analytical technique to quantitatively measure the polytype contents using X-ray diffraction (XRD). According to their procedure, 25 integrated intensities are selected to calculate the concentration of the five most common polytypes $(2 \mathrm{H}, 3 \mathrm{C}, 4 \mathrm{H}$, $6 \mathrm{H}$ and $15 \mathrm{R}-\mathrm{SiC}$ ), using a multi-regression technique. To evaluate the possibility of polytype transformation during dynamic deformation, 
recovered and fractured $\mathrm{SiC}$ specimens were characterized using XRD, following the procedures outlined by Tanaka and Iyi [45]. Each specimen was scanned by X-rays three times, and the average data, as well as their standard deviation, are listed in Tables 1 and 2. The results show that $6 \mathrm{H}-\mathrm{SiC}$ was the dominant polytype in both $\mathrm{SiC}$, and that the amount of $6 \mathrm{H}$ increases as the dynamic compressive stress increases. The $6 \mathrm{H}-\mathrm{SiC}$ content was about $73 \pm 5 \%$ after low compressive stresses. For loading above $4.5 \mathrm{GPa}$
Table 1. Polytypes of SiC-I after impact

\begin{tabular}{lcrrrr}
\hline Impact stress & $2 \mathrm{H}(\%)$ & $3 \mathrm{C}(\%)$ & $4 \mathrm{H}(\%)$ & $6 \mathrm{H}(\%)$ & $15 \mathrm{R}(\%)$ \\
\hline 0 & $0 \pm 0$ & $9 \pm 3$ & $3 \pm 2$ & $78 \pm 1$ & $10 \pm 5$ \\
$0.8 \mathrm{GPa}$ & $4 \pm 3$ & $14 \pm 3$ & $6 \pm 1$ & $68 \pm 4$ & $8 \pm 1$ \\
$1.4 \mathrm{GPa}$ & $2 \pm 1$ & $2 \pm 1$ & $4 \pm 1$ & $78 \pm 4$ & $15 \pm 3$ \\
$3.0 \mathrm{GPa}$ & $6 \pm 3$ & $0 \pm 0$ & $14 \pm 1$ & $73 \pm 1$ & $8 \pm 3$ \\
$4.2 \mathrm{GPa}$ & $1 \pm 1$ & $9 \pm 9$ & $5 \pm 3$ & $76 \pm 5$ & $10 \pm 4$ \\
$4.3 \mathrm{GPa}$ & $2 \pm 2$ & $20 \pm 9$ & $3 \pm 2$ & $68 \pm 3$ & $7 \pm 3$ \\
$4.5 \mathrm{GPA}$ & $2 \pm 2$ & $3 \pm 3$ & $5 \pm 1$ & $82 \pm 1$ & $8 \pm 1$ \\
$4.6 \mathrm{GPa}^{\mathrm{a}}$ & $0 \pm 0$ & $6 \pm 3$ & $3 \pm 3$ & $80 \pm 3$ & $11 \pm 3$ \\
$4.8 \mathrm{GPa}^{\mathrm{a}}$ & $1 \pm 1$ & $2 \pm 2$ & $2 \pm 1$ & $95 \pm 2$ & $1 \pm 1$ \\
\hline
\end{tabular}

${ }^{\text {a }}$ Fractured.

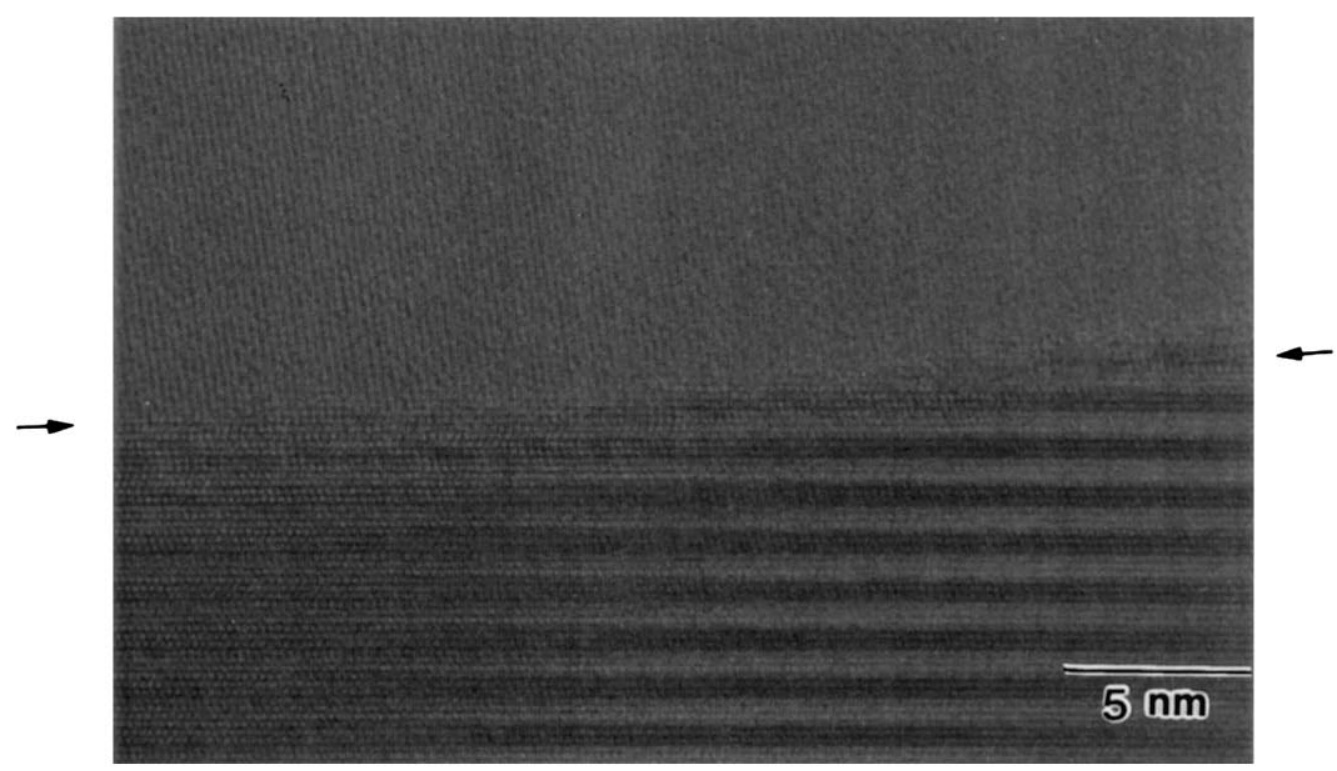

(a)

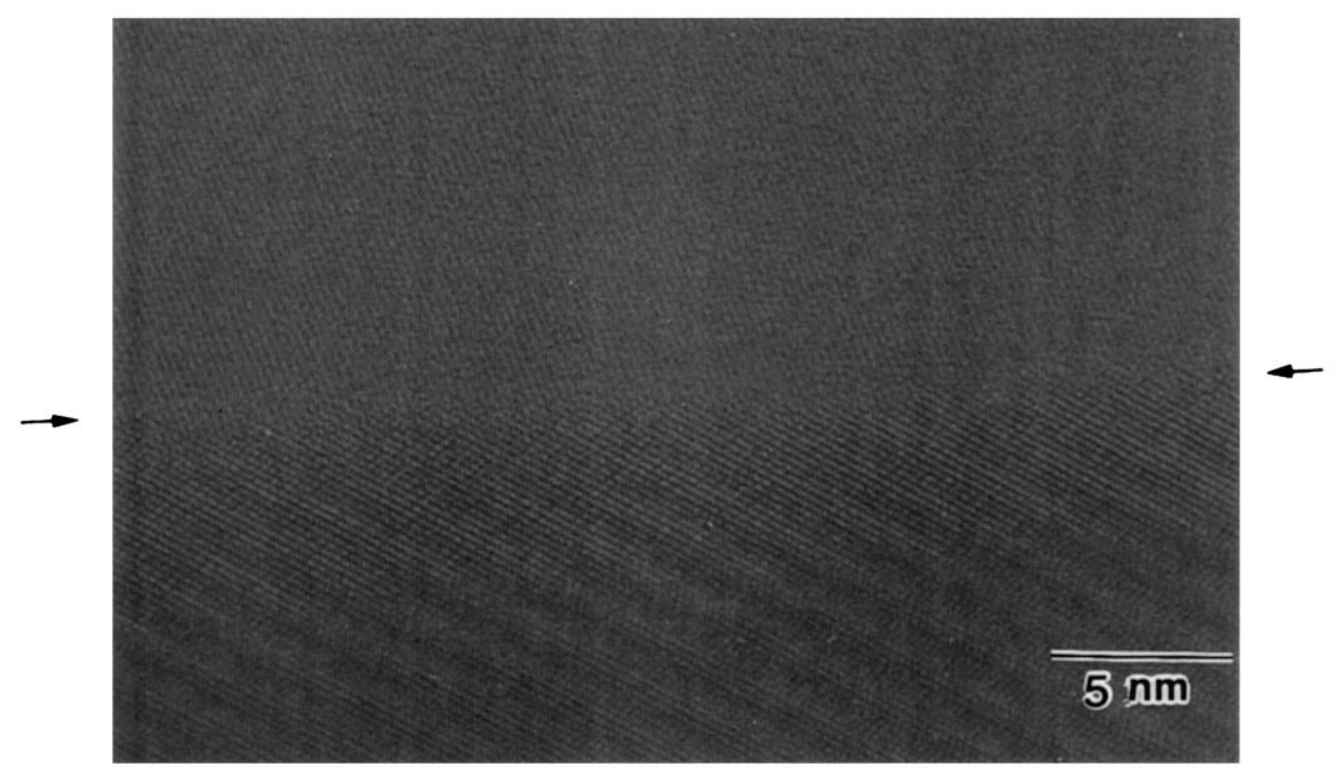

(b)

Fig. 4. (a,b) TEM micrographs of grain boundary, indicated by arrows, showing the absence of an intergranular phase: (a) SiC-I, (b) SiC-II; (c) intergranular inclusion in isolated region. 
(c)

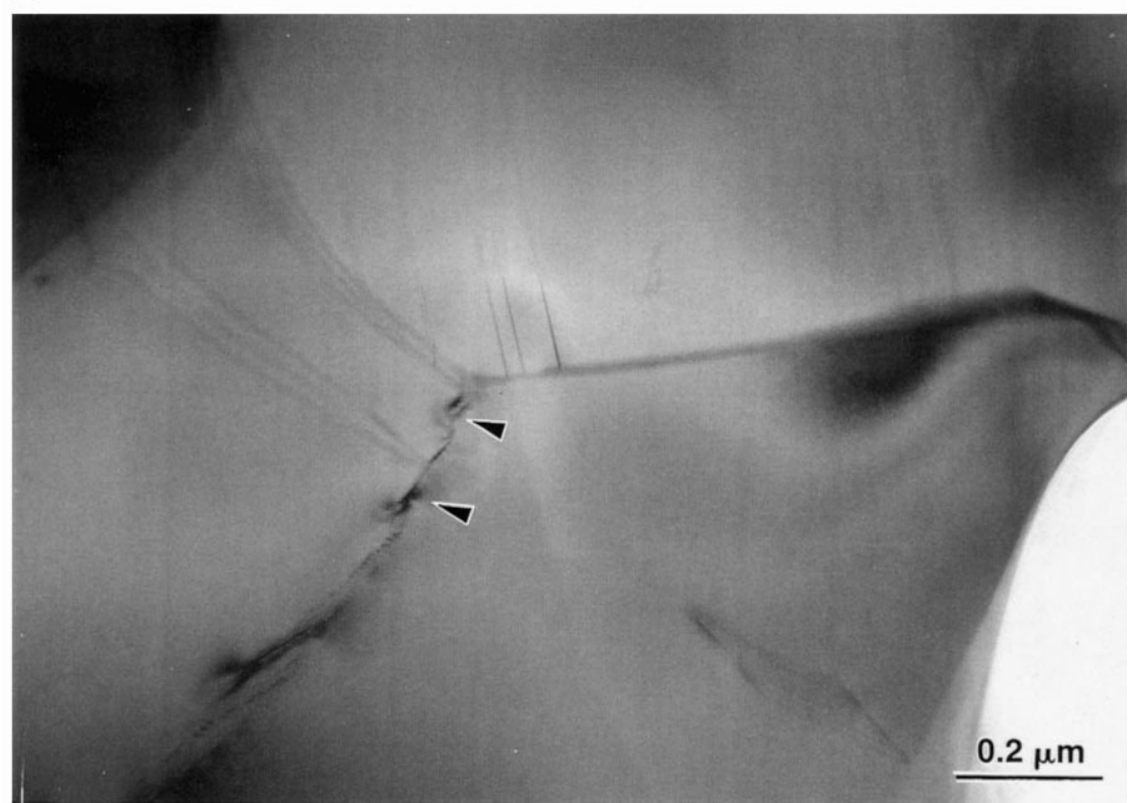

Fig. 4 (continued)

the $6 \mathrm{H}-\mathrm{SiC}$ content increased significantly, as shown in Fig. 6.

Tanaka and Iyi [45] pointed out that polycrystalline $\mathrm{SiC}$ does not diffract exactly the same as a single crystal, and this XRD technique does not consider lattice defects, such as stacking faults. Dislocations and stacking faults can create a strain field to cause a change in the peak width and height. For example, Pujar and Cawley [46] demonstrated that stacking faults in $3 \mathrm{C}-\mathrm{SiC}$ powder produce an additional peak, higher background noise and higher intensity from a few diffraction planes. Tateyama et al. [47] also demonstrated that the density of stacking faults in $3 \mathrm{C}-\mathrm{SiC}$ affects the relative intensity. Although either stacking faults or dislocations influence the integrated intensity significantly, the tails of the broadened peaks may introduce some measurement errors. Nevertheless, this XRD technique does provide a qualitative trend; the measured $6 \mathrm{H}-\mathrm{SiC}$ content varies from 70

Table 2. Polytypes of SiC-II after impact

\begin{tabular}{lrrrrr}
\hline Impact stress & $2 \mathrm{H}(\%)$ & $3 \mathrm{C}(\%)$ & $4 \mathrm{H}(\%)$ & $6 \mathrm{H}(\%)$ & $15 \mathrm{R}(\%)$ \\
\hline 0 & $1 \pm 0$ & $8 \pm 3$ & $4 \pm 1$ & $70 \pm 3$ & $17 \pm 1$ \\
$0.9 \mathrm{GPa}$ & $2 \pm 1$ & $12 \pm 7$ & $5 \pm 1$ & $72 \pm 5$ & $11 \pm 3$ \\
$1.3 \mathrm{GPa}$ & $2 \pm 0$ & $16 \pm 6$ & $3 \pm 0$ & $71 \pm 4$ & $8 \pm 2$ \\
$2.5 \mathrm{GPa}$ & $1 \pm 1$ & $7 \pm 5$ & $5 \pm 2$ & $76 \pm 5$ & $11 \pm 2$ \\
$2.8 \mathrm{GPa}$ & $0 \pm 0$ & $13 \pm 6$ & $6 \pm 2$ & $70 \pm 7$ & $12 \pm 2$ \\
$4.2 \mathrm{GPa}$ & $4 \pm 4$ & $12 \pm 4$ & $5 \pm 0$ & $68 \pm 1$ & $12 \pm 1$ \\
$4.7 \mathrm{GPa}$ & $2 \pm 2$ & $2 \pm 2$ & $6 \pm 1$ & $80 \pm 2$ & $10 \pm 1$ \\
$4.8 \mathrm{GPa}$ & $1 \pm 1$ & $9 \pm 7$ & $4 \pm 2$ & $80 \pm 4$ & $7 \pm 1$ \\
$4.8 \mathrm{GPa}$ & $0 \pm 0$ & $3 \pm 2$ & $4 \pm 3$ & $87 \pm 1$ & $7 \pm 1$ \\
$4.9 \mathrm{GPa}^{a}$ & $1 \pm 1$ & $2 \pm 2$ & $3 \pm 2$ & $89 \pm 4$ & $5 \pm 1$ \\
\hline
\end{tabular}

${ }^{a}$ Fractured. to $90 \%$. Our results indicate that the crystal structure of $\mathrm{SiC}$ changes during the dynamic deformation, and suggest micro-plasticity prior to failure. The polytype transformation by external stresses can be readily understood, because the difference in the polytype structures is only in the stacking sequence of close-packed planes. Indeed, Yang and Pirouz [48] report a $6 \mathrm{H} \rightarrow 3 \mathrm{C}$ transformation induced in the immediate vicinity of indentation; Shockley partial dislocations were proposed to cause this polytype transformation.

TEM analysis indicated that the as-pressed SiC-I had extensive stacking faults. Figure 5(a) shows a grain with profuse stacking faults/polytypes. The selected area diffraction (SAD) of Fig. 5(b) reveals two important features:

1. The brightness of spots varies with a periodicity of six. Two bright spots are marked by arrows. There are five spots between them. Song et al. [49] have shown that this periodicity is characteristic of the $6 \mathrm{H}$ polytype.

2. The diffraction spots exhibit streaking perpendicular to the trace of the stacking faults. This streaking was also observed by Song et al. [49]. The diffraction pattern was identified by Song et al. [49]. It represents the $\langle 1100\rangle$ zone of the $6 \mathrm{H}$ or the $<211>$ zone of the $3 \mathrm{C}$ polytype. The streaking, which occurs along the [0001] direction, enables the identification of the plane of the stacking faults: (0001). Figure 5(c) shows how the passage of a partial dislocation creates a stacking fault. The $1 / 3[10 \overline{1} 0]$ dislocation traveled from left to right and produces a change in the 
$6 \mathrm{H}$ stacking sequence ( $\mathrm{ABCACBABCACB} \ldots$...) to $\mathrm{BCABC}$. This corresponds to the $3 \mathrm{C}$ polytype. Song et al. [49] explain these shuffles in greater detail.

Despite the abundance of stacking faults, no dislocations were seen in the as-pressed SiC-I. The aspressed SiC-II also had extensive stacking faults and a higher dislocation density than SiC-I; the dislocations in the as-pressed SiC-II were usually in the vicinity of grain boundaries.

\subsection{Microstructural defects in as-pressed $\mathrm{SiC}$ and ruptured fragments}

The stacking fault energy in $6 \mathrm{H}-\mathrm{SiC}$ has been estimated to be 1.9 and $2.5 \mathrm{~mJ} / \mathrm{m}^{2}$, by Stevens [50] and Maeda et al. [51], respectively. This stacking fault energy is very low, compared with the stacking fault energies of f.c.c. metals. For example, the stacking fault energies for $\mathrm{Cu}, \mathrm{Al}$, and $\mathrm{Ni}$ are 163,238 , and $300 \mathrm{~mJ} / \mathrm{m}^{2}$, respectively [52]. As a result, stacking faults can be easily generated in $\mathrm{SiC}$. On the other hand, dislocations are not as common as stacking faults. Amelinckx et al. [53] examined the $6 \mathrm{H}-\mathrm{SiC}$ structure, and concluded that there are two types of dislocations, with the following two Burgers' vectors: (1) $\mathbf{b}=\mathbf{a}[112 \overline{2} 0]$ and (2) $\mathbf{b}=\mathbf{c}[0001]$. Pilyankevich and Britun [54] studied the dislocations in $\mathrm{SiC}$ using electron microscopy and concluded that only Shockley partial dislocations with $\mathbf{b}=\mathbf{a}[1 \overline{1} 00]$ are mobile.

The dynamically ruptured fragments of SiC-I (Fig. 7) contained extensive stacking faults and dislocations. Figure 7(a) shows stacking faults that are

(a)

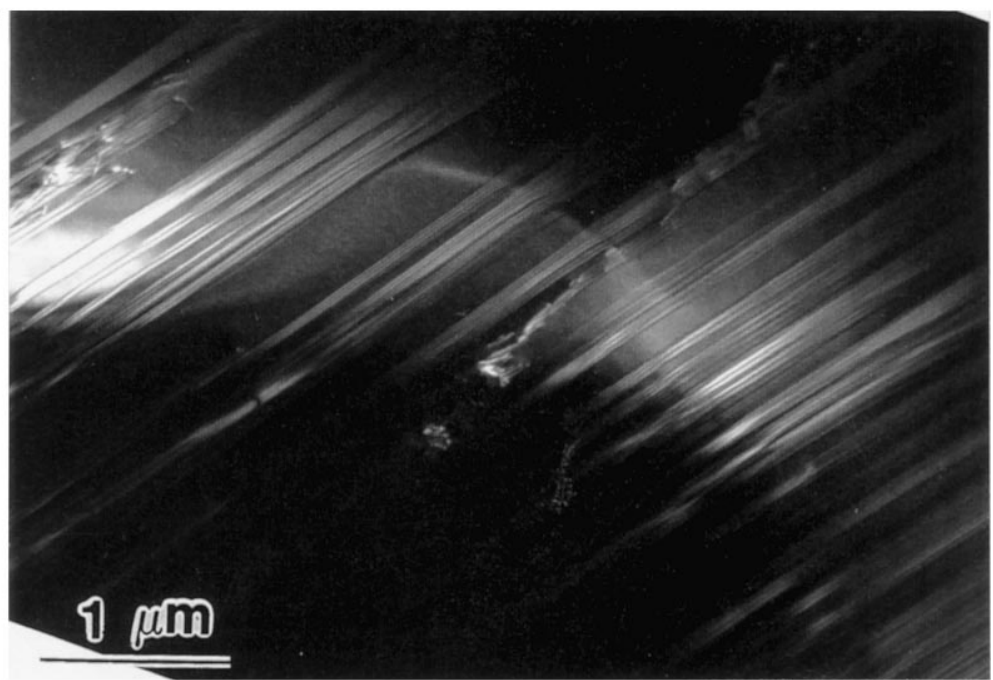

(b)

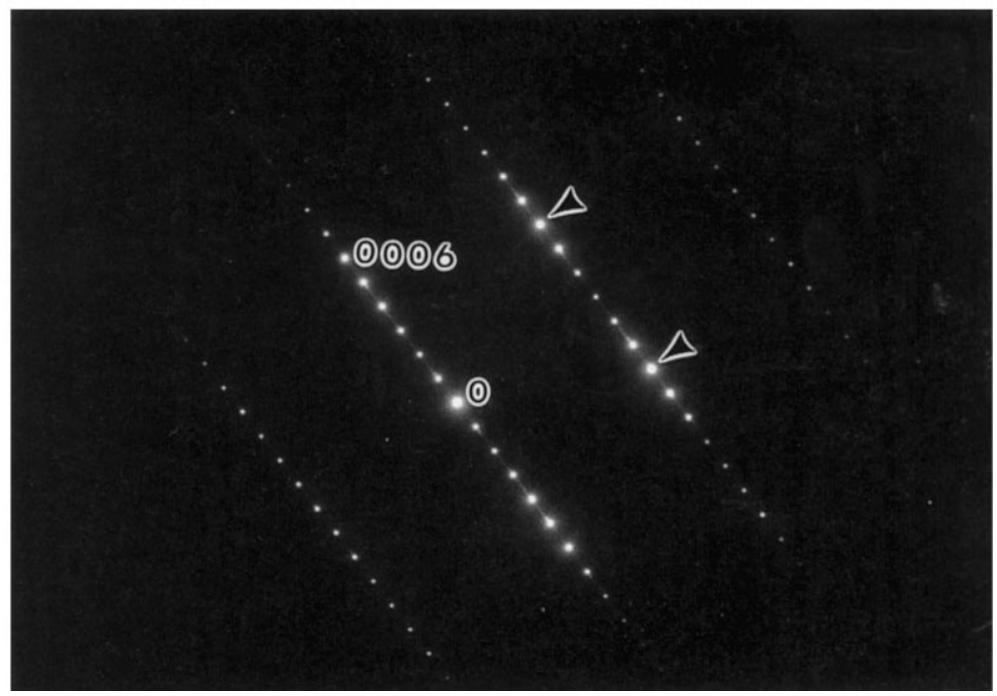

Fig. 5. TEM micrograph of as-pressed SiC-I: (a) SiC grain with extensive stacking faults (DF); (b) corresponding diffraction pattern; (c) schematic of $6 \mathrm{H}$ structure and partial dislocation, generating stacking fault (adapted from Song et al. [49]). 
(c)

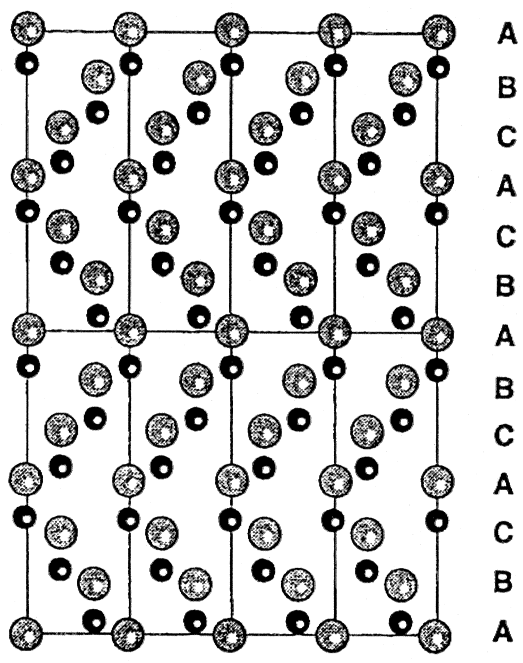

Si $\bigcirc \mathrm{C}$

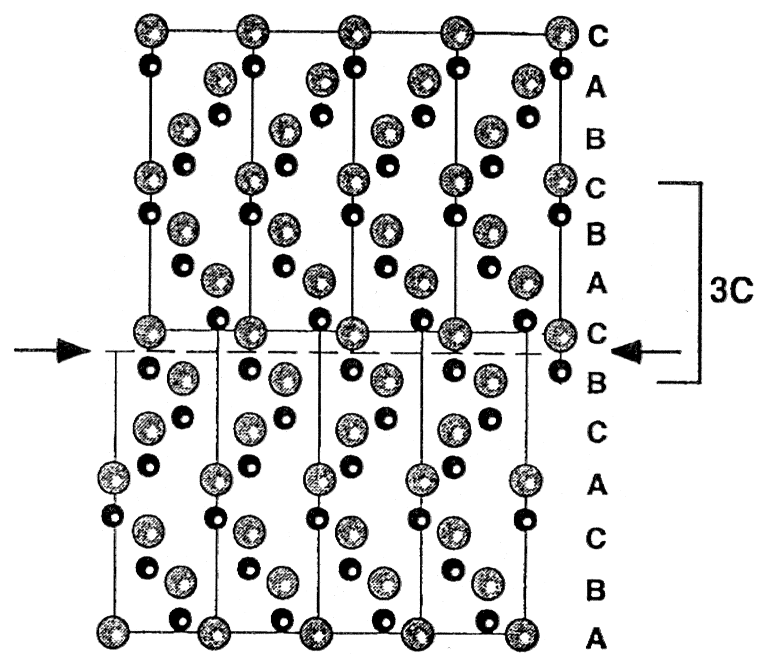

(1210)

Fig. 5 (continued)

apparently generated at the grain boundaries and emitted into the grain interiors. The presence of dislocations in the fragments is a marked difference in the microstructure; Fig. 7(b), dark field (DF) shows stacking faults emanating from a grain boundary and dislocations. This type of activity is thought to result from the dynamic deformation. It should be mentioned that only isolated grains showed the presence of dislocations. Nevertheless, it is thought that these microplasticity events are very important, since they can initiate failure. The density of dislocations in SiC-II also increased significantly during dynamic deformation. This is consistent with observations by Stevens [55], who showed that both dis-

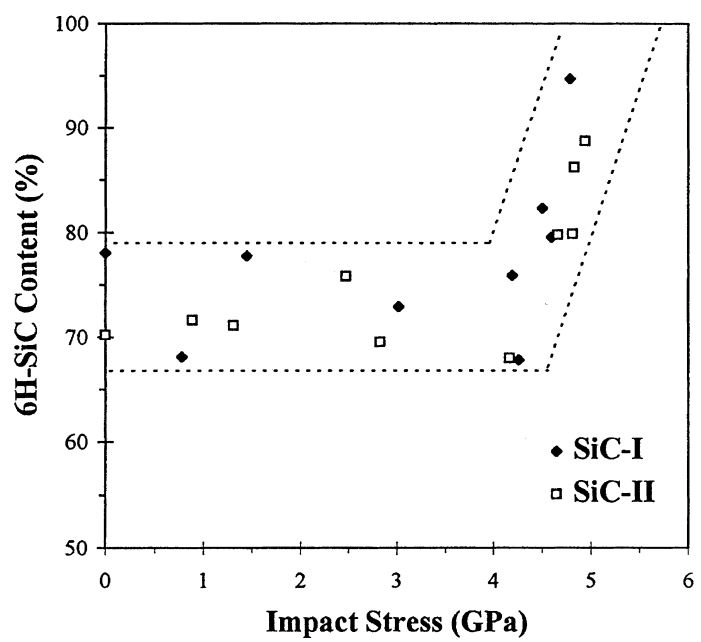

Fig. 6. 6H-SiC content after dynamic deformation. locations and stacking faults can be induced in $\mathrm{SiC}$ crystals during the failure process, even at room temperature. Maeda et al. [51] also demonstrated that the local stresses generated by indentation can create dislocations; Seo et al. [56] emphasize the insertion and extraction of stacking fault layers.

\subsection{Micromechanical models for fracture}

Compressive failure of brittle materials has received extensive attention, and several micromechanical models (initially derived for homogeneous materials, without consideration of microstructural features, such as grain boundaries) have been developed $[1,2]$. There are a number of microstructural mechanisms that have been identified as failure initiation sites in compressive loading; the ones briefly described below are the most likely failure initiation mechanisms for SiC. There is a hierarchy of defects, which varies according to the processing and composition of material. Thus, SiC-I and $\mathrm{SiC}-\mathrm{II}$ may have a different mix of defects, resulting in differences in their mechanical response. The principal mechanisms are:

(a) Flaws [Fig. 8(a)]. These ellipsoidal defects have been treated in great rigor by a considerable number of researchers. Figure 8(a) shows a flaw that was produced by the debonding along a grain boundary. This is a common occurrence in polycrystalline brittle materials, because the grain boundaries often contain foreign atoms and second phases. Upon compression, there is slippage on the flaw, producing tensile stresses at the extremities and triggering the formation of 
cracks. Dummer et al. [57] treated this problem, for tungsten; grain boundary debonds were found to be initiation sites for intergranular fracture.

(b) Voids and inclusions [Fig. 8(b)]. These are classic failure initiation sites in ceramics. They are almost always present and result from imperfect processing procedures. These defects are often located at the grain boundaries. In $\mathrm{SiC}$, graphite inclusions were observed. Figure 4(c) shows a grain-boundary inclusion.

(c) Stress concentration due to dislocation pileups [Fig. 8(c)]. Microcracks can also be nucleated from piled up dislocations, as originally proposed by Zener [58] and Stroh [59], and shown in Fig. 8(c). Applied stresses generate dislo-

(a)

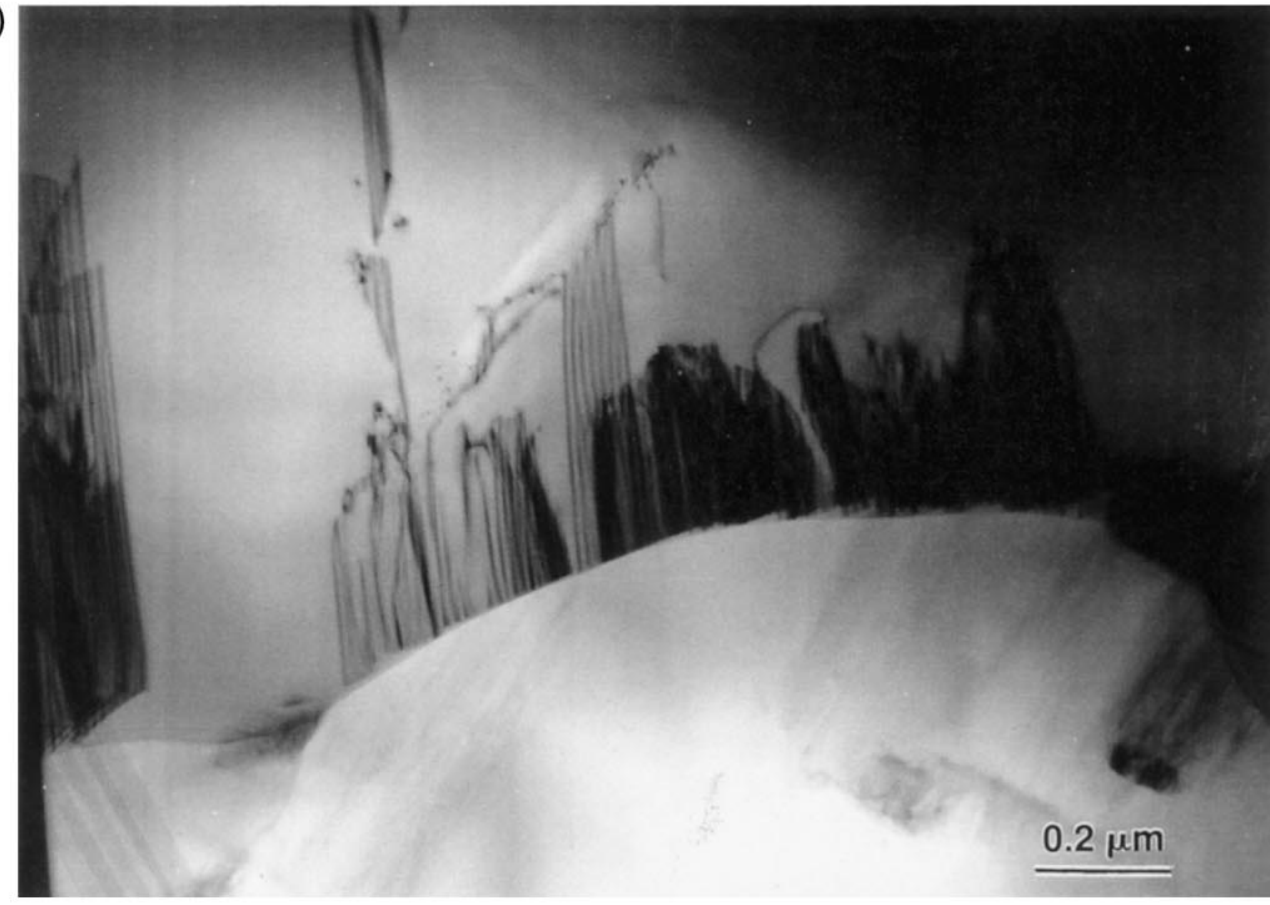

(b)

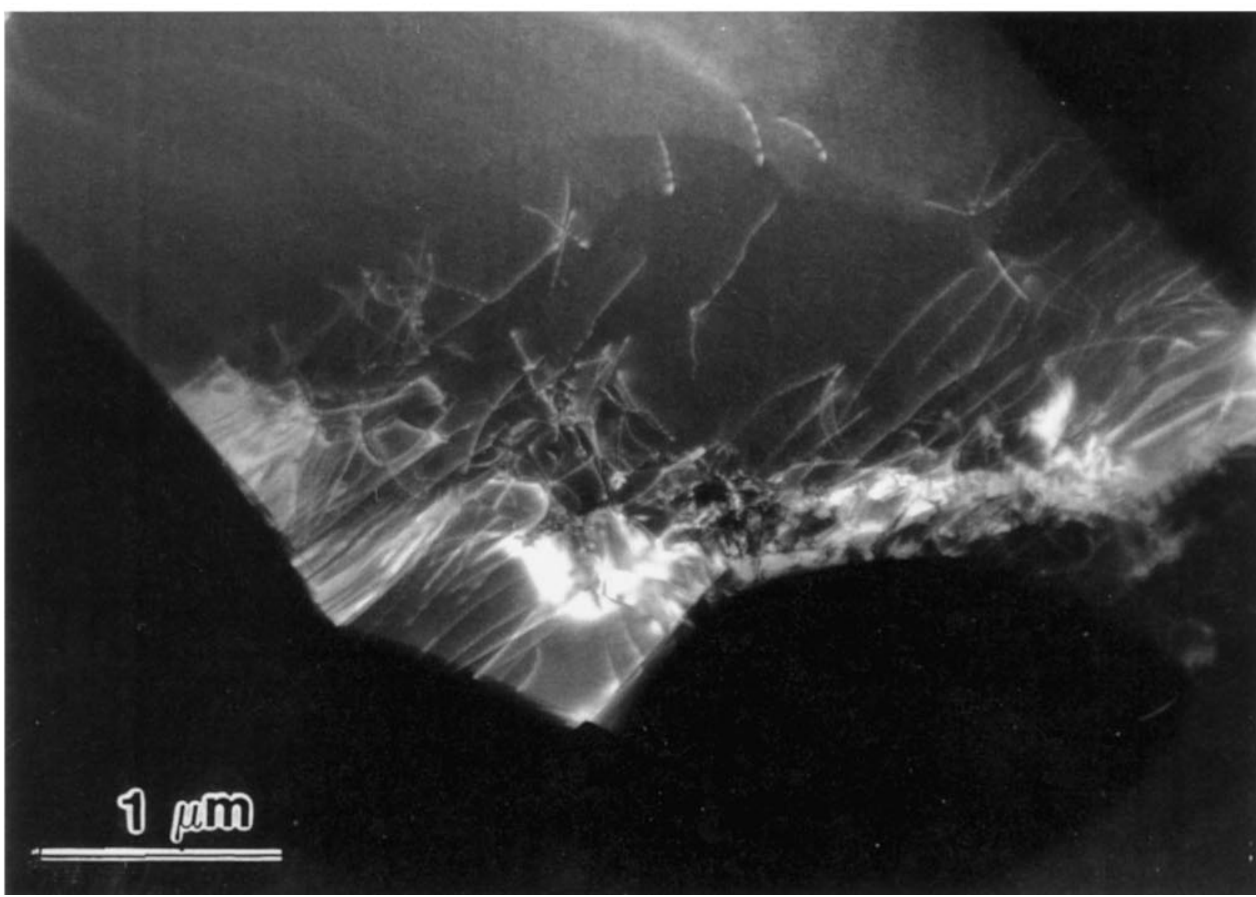

Fig. 7. TEM micrograph of dynamically ruptured $\mathrm{SiC}$ fragments: (a) $\mathrm{SiC}$ grain with stacking faults emanating from grain boundaries; (b) $\mathrm{SiC}$ grain with stacking faults and dislocations. 
cations through Frank-Read or Stroh sources. These dislocations are often stopped and piled up along their slip planes at obstacles, such as grain boundaries. A high shear stress is generated at the leading dislocation of the piled-up dislocations, and this stress can be relaxed through the nucleation of a microcrack (ZenerStroh crack). Coalescence of these microcracks along grain boundaries results in intergranular fracture.

(d) Stress concentration due to twinning and stacking faults [Fig. 8(d)]. Lankford [6, 7] proposed a transgranular fracture model through dilatant cracks. The applied stress nucleates a twin, which impinges on the grain boundary. Since grains are misoriented along the grain boundary, a tensile stress, perpendicular to the compressive stress, is induced on the grain boundary. The induced tension stress initiates and propagates a dilatant crack, leading to the transgranular fracture. This type of transgranu-

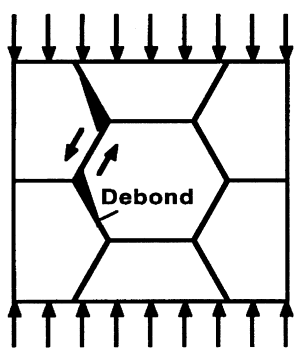

(a)

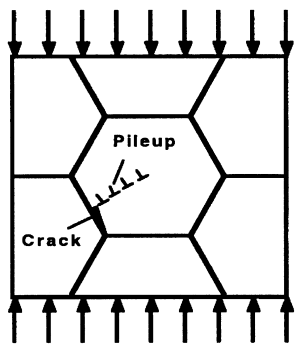

(c)

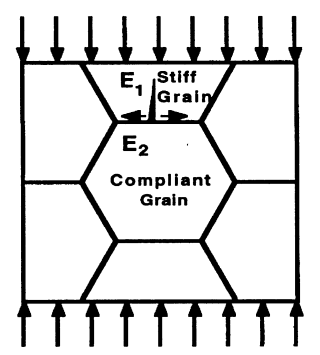

(e)

Fig. 8. Schematic overview of principal damage initiation mechanisms in $\mathrm{SiC}$ : (a) grain boundary debonds and voids; (b) foreign particles, such as inclusions; (c) dislocation pileups, leading to Zener-Stroh cracks; (d) twins and stacking faults; (e) dilatant crack produced by elastic anisotropy (see Appendix A). lar dilatant microcrack has been observed and characterized in granites [60].

Specific to SiC, Song et al. [49] discuss the formation of cracking along the basal plane (0001) of the $6 \mathrm{H}$ phase. These cracks are initiated by partial dislocations and stacking faults, that produce stress concentrations.

(e) Elastic anisotropy effect [Fig. 8(e)]. This effect, which is shown in schematic fashion in Fig. 8(e), is analyzed in detail in Appendix A. Different grains have different stiffnesses, due to elastic anisotropy. Under a compressive applied traction, internal tensile stresses can be developed. A simple FEM calculation is carried out in Appendix A; it is shown that the "effective" Young's modulus varies between 375 and 475 $\mathrm{GPa}$. This can generate tensile stresses, perpendicular to the loading direction, of $220 \mathrm{MPa}$, when the external traction is $5 \mathrm{GPa}$ (compressive strength). These stresses are higher along the grain boundaries and inside the stiffest grains. Ghahremani et al. [61], and Ghahremani and Shih [62] have shown that high stress concentrations can be reached at triple points in polycrystalline aggregates subjected to compressive stresses. Espinosa et al. [63] modeled the compressive failure of $\mathrm{Al}_{2} \mathrm{O}_{3}$ and $\mathrm{SiC}$.

It should be mentioned that initiation mechanisms (a), (c), and (d) produce intergranular microcracks, whereas (b) and (e) produce transgranular microcracks. It is easy to envision changes in the crack propagation paths when intergranular microcracks reach triple points; they can transform fracture to a transgranular mode. The inverse situation, involving the change from transgranular to intergranular, can also be envisioned. Hence, these initiation mechanisms do not dictate the mode of fracture.

\subsection{Rod impact of $\mathrm{SiC}$}

SiC-II was used in the impact experiment, which defeated the projectile on the interface (interface defeat). The experiment was carried out by Hauver et al. [22-25]; the experimental details can be found in these sources. A schematic diagram of the damage pattern is presented in Fig. 9(a). The comminution zone (also called Mescall zone), cone cracks, and lateral cracks can be clearly seen in Fig. 9(b), and these damage patterns have been identified by Shockey et al. [64], Viechnicki et al. [65], and Meyers [66], in other types of impact tests on ceramics. The high magnification micrograph [Fig. 9(c)] clearly indicates the intergranular fracture mode in the comminution zone. The comminuted particle size was around $5 \mu \mathrm{m}$, which was similar to the initial grain size. The cross-section of the comminuted zone has an elliptical morphology, and there is a thin, undamaged frontal layer, separating the comminution zone and the impact surface. This 


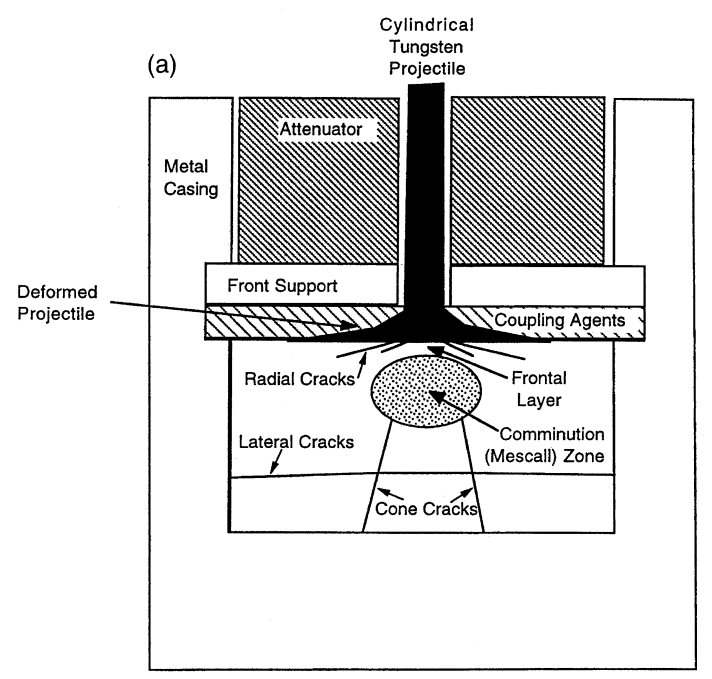

(b)

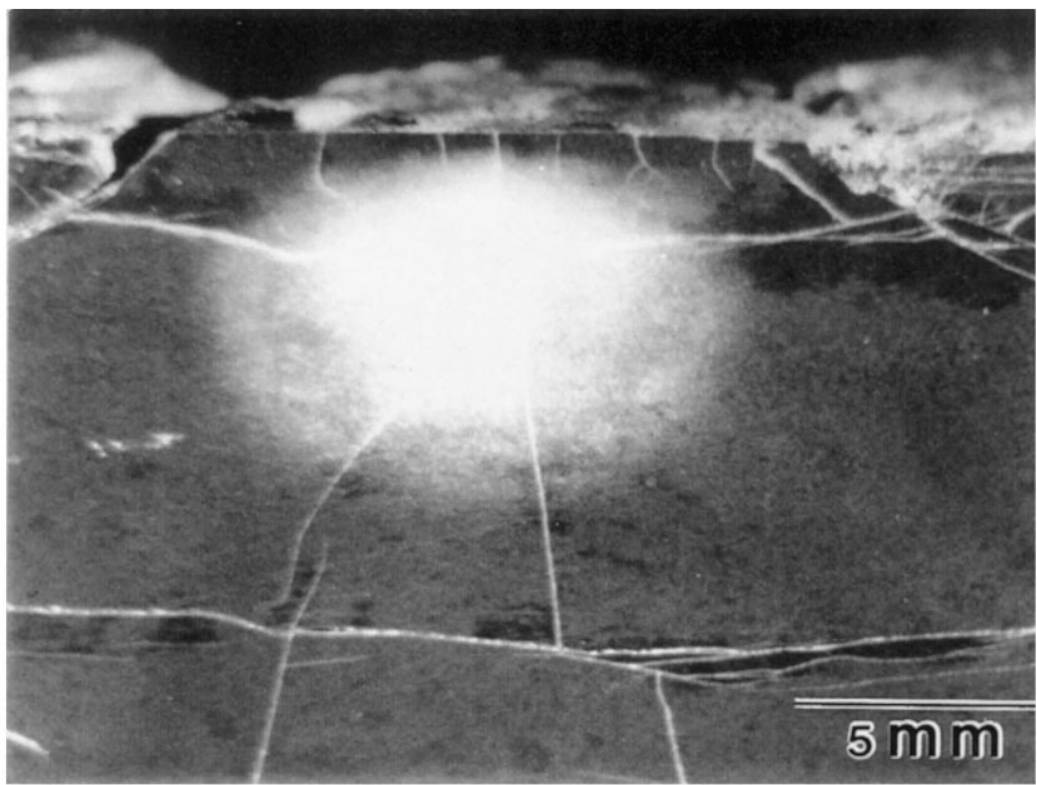

(c)

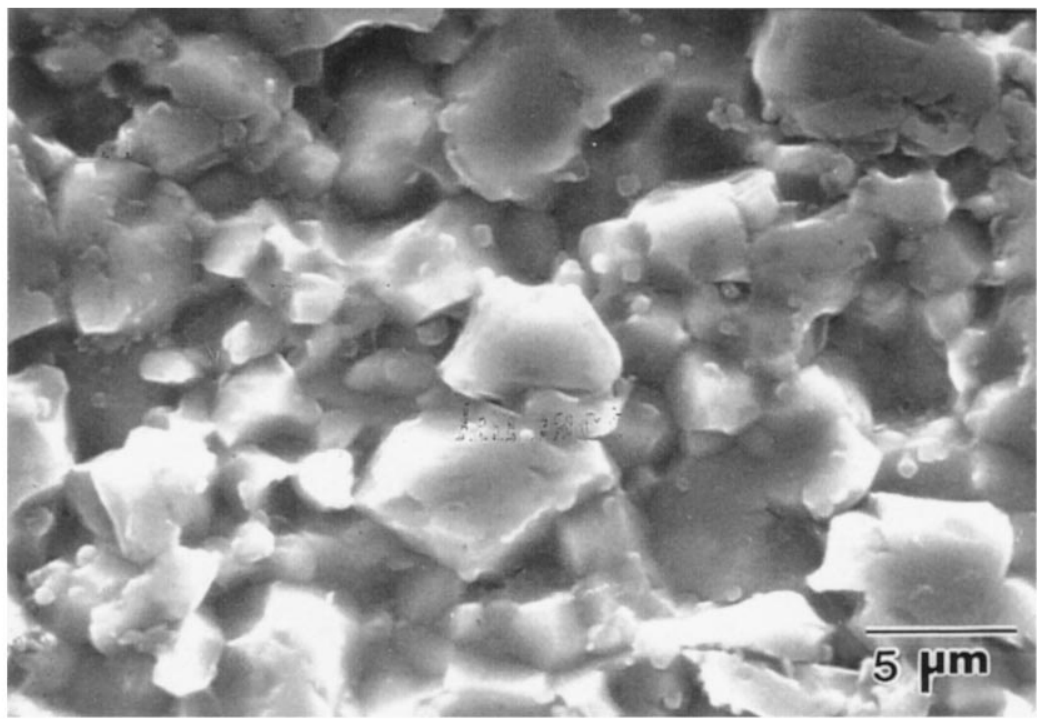

Fig. 9. Rod impact of $\mathrm{SiC}$ (Hauver et al. [22-24]): (a) schematic diagram of the damaged SiC; (b) overview micrograph of recovered $\mathrm{SiC}$; (c) micrograph with high magnification of the comminution zone. 
layer contains visible radial cracks, but has no apparent comminution. Hauver et al. [22, 23] hypothesized that this thin, undamaged layer is related to a healing process, resulting from high temperatures at the surface during the plastic deformation and flow of the projectile. Indeed, Shih et al. [67] demonstrated that $\mathrm{SiC}$ granules can be densified during high strain $(\gamma>10)$, high-strain-rate $(\dot{\varepsilon} \approx 3 \times$ $10^{4} \mathrm{~s}^{-1}$ ) deformation, through a localized heating; however, there was no apparent shear flow in the vicinity of this frontal layer. An alternative explanation is provided here (see Section 3.6). To understand the cause of the frontal layer, it is necessary to estimate the magnitude of the stress at the impact interface.

A penetrator from cylindrical tungsten alloy (4.93 $\mathrm{mm}$ diameter and $17.7 \mathrm{~g} / \mathrm{cm}^{3}$ density) was used in the impact experiment. The initial impact velocity was $1579 \mathrm{~m} / \mathrm{s}$. After penetrating through the shock-wave attenuator and the front support, the impact velocity at the ceramic front face was approx. $1482 \mathrm{~m} / \mathrm{s}$ [68]. At a distance from the interface smaller than the radius of the projectile, a state of uniaxial strain can be assumed, because this region was shielded from the radial release waves. The hydrostatic steady state pressure $\left(P_{\mathrm{H}}\right)$ generated by the advancing projectile can be calculated, using the impact velocity $(V)$ and projectile density $\left(\rho_{\mathrm{p}}\right)$, through the Bernoulli equation:

$$
P_{\mathrm{H}}=\frac{1}{2} \rho_{\mathrm{P}} V^{2} \approx 19 \mathrm{GPa} .
$$

This estimation is based on an assumption that, after impact, the velocities of both the projectile and ceramic target are zero. The calculation provides the lower limit for the impact pressure.

At the interface, rod-impact also generates a shock pressure, which was attenuated rapidly across the ceramic target. Using the simplest equation of state $\left(U_{\mathrm{s}}=C+S U_{\mathrm{p}}\right.$, where $U_{\mathrm{s}}$ is the shock velocity, $C$ is the sonic velocity, $S_{1}$ is an empirical parameter, and $U_{\mathrm{p}}$ is the particle velocity), the pressure on the projectile $\left(P_{\mathrm{p}}\right)$, equal to the pressure of the target $\left(P_{\mathrm{t}}\right)$, can be estimated, as outlined by Meyers [66]. $C_{\mathrm{p}}$ is the sonic velocity of the projectile $(4.029 \mathrm{~km} / \mathrm{s}$ for $W[56]), S_{\mathrm{p}}$ is the parameter of the equation of state for the projectile (1.237 for $W$ [69]), $C_{\mathrm{t}}$ is the sonic velocity of the ceramic target $(8.19 \mathrm{~km} / \mathrm{s}$ for $\mathrm{SiC}), S_{\mathrm{t}}$ is the parameter of the equation of state for the ceramic target $\left(0.88\right.$ for $\mathrm{SiC}$ [70]), and $U_{\mathrm{pp}}$ and $U_{\mathrm{pt}}$ are the particle velocities in the projectile and the target, respectively. The following equations are used:

$$
\begin{gathered}
P_{\mathrm{p}}=\rho_{\mathrm{p}}\left(C \mathrm{p}+S_{\mathrm{P}} U_{\mathrm{PP}}\right) U_{\mathrm{PP}}=\rho_{\mathrm{t}}\left(C_{\mathrm{t}}+S_{\mathrm{t}} U_{\mathrm{Pt}}\right) U_{\mathrm{Pt}} \\
=P_{\mathrm{t}} \\
V-U_{\mathrm{pp}}=U_{\mathrm{pt}}
\end{gathered}
$$

$V$ is the projectile (impact) velocity. The interface undergoes a shock pressure as high as $32 \mathrm{GPa}$, which is an upper estimate for the impact pressure. The shock pressure is obtained from the hydrodynamic approach, derived for planar impact. A more accurate prediction of the maximum principal and shear stresses was obtained by Espinosa et al. [63]. The stress state in target for the rod impact is much more complicated, because of the point loading condition. Nevertheless, in the frontal layer $(380 \mu \mathrm{m}$ thick), the impact can be considered as a planar impact, and the considered approach is fairly appropriate. The Hugoniot elastic limit (HEL) of $\mathrm{SiC}$ is about $15 \mathrm{GPa}$ [71], which is smaller than the estimated hydrostatic pressure (19 GPa) and shock pressure (32 GPa). Conventionally, the Hugoniot elastic limit is considered as the onset of brittle fracture (comminution) or ductile plastic deformation [71]. The thin frontal layer undergoes a stress higher than the Hugoniot elastic limit, and does not have apparent brittle fracture, implying the presence of plastic deformation. It will be described how the lateral confinement impedes crack growth in Section 3.6. Compressive stresses due to bending are another possible source of confinement in the interface region.

\subsection{Microstructure and lateral constraint of the frontal layer}

Transmission electron microscopy of the regions adjoining the impact of the projectile was carried out by extracting foils parallel to the impact direction (and parallel to the frontal plane of $\mathrm{SiC}$ ). Figure 10 shows a low magnification shadowgraph of the thin foil. The jagged edge represents the perforation. The position of the foil with respect to the projectile is shown in the left-hand side. It is taken from the center of the impact. Several cracks emanate from the impact surface and are sketched in the righthand side. One of them was fully documented and is marked as Area 2. A transparent area right at the impact face was observed and documented; it is marked as Area 1. An area of approx. $50 \mu \mathrm{m} \times 200 \mu \mathrm{m}$ was observed (the rim of the perforation). Thus, the results presented represent the typical features of this region. The cracks were intergranular, as shown in Fig. 11(a). Four major cracks emanated from the vicinity of the impact face and they could be followed for approx. $0.1 \mathrm{~mm}$. The KRATOS $1 \mathrm{MeV}$ TEM (also at the NCEM) was used for this purpose. Figure 11(b) shows a montage of micrographs using this high voltage, which enabled transparency of a much larger area. There is evidence of bifurcation (marked by arrows in the figure). Nevertheless, there is no generalized grain boundary separation in this region, in contrast with the comminuted region 

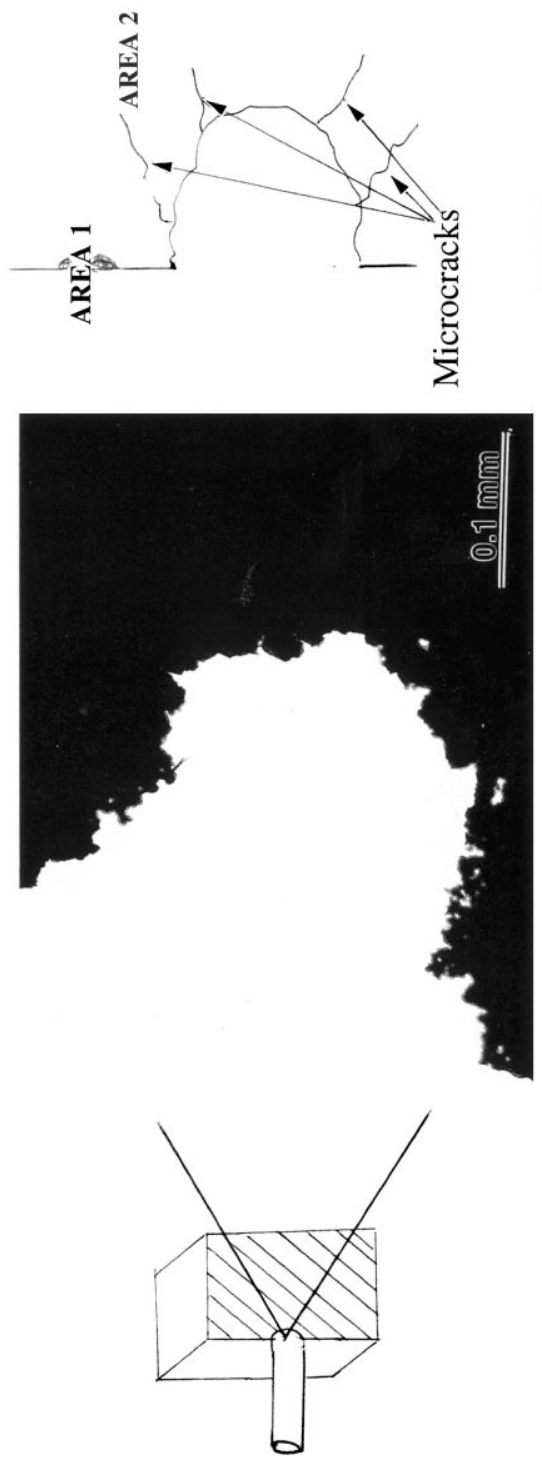

adjoining it. Thus the multiplane microcracking computational approach implemented by Espinosa [72] captures the principal features of crack initiation and fragmentation and is well suited for the simulation of the dynamic response of ceramics.

A grain with profuse dislocations is shown in Fig. 12. These dislocations tend to be straight and are aligned along preferred crystallographic directions. The dark field image of Fig. 12(b) enables the identification of two clear orientations. It should be mentioned that this dislocation density is significantly higher than the one observed in the fragmented Hopkinson bar specimens (SiC-II).

Compressive failure of brittle material is different from tensile failure. In compression, microcracks are nucleated at preexisting flaws and local tensile fields are required to propagate the microcracks. These local tensile stress fields can have several origins, and one of the origins is elastic incompatibility, described in Section 3.4 and Appendix A. Compressive failure is associated with the growth of these compression-induced tension cracks. An increase in the lateral pressure can suppress the growth of tension cracks. Microscopically, the suppression of the tension cracks can be related to the localized inelastic deformation around the crack tips, as referred to as the plastic zone in Fig. 13(a). Horii and Nemat-Nasser [73] developed a formulation for the tension cracks and plastic zones, and defined brittle, ductile and transitional modes for the compressive failure. The brittle failure is associated with the unstable growth of tension cracks; the ductile failure is dominated by the growth of plastic zones. The transitional mode involves both plastic zones and tension cracks: plastic zones are developed in the early stage, but the final failure is determined by the unstable growth of tension cracks. The regions of dominance of these three modes are determined by the lateral confinement $\left(\sigma_{22} / \sigma_{11}\right)$ and a ductility parameter $(\Delta)$, as shown in Fig. 13(b); the ductility parameter is defined as:

$$
\Delta=\frac{K_{\mathrm{c}}}{\tau_{y} \sqrt{\pi c}},
$$

where $K_{\mathrm{c}}$ is the critical stress intensity factor, $\tau_{y}$ is the shear strength, and $2 c$ is the flaw size. Since the Hugoniot elastic limit is conventionally considered as the maximum stress for elastic response under uni-axial strain, the shear strength can be approximated as half of the Hugoniot elastic limit $\left(\tau_{y}=\mathrm{HEL} / 2\right)$. As shown in TEM micrographs (Fig. 11), cracks propagate along grain boundaries, so that the flaw size (2c) can be approximated by the grain size. $K_{\mathrm{c}}$ of $\mathrm{SiC}$ is $4.1 \mathrm{MPa} \sqrt{\mathrm{m}}$, and the ductility parameter can then be estimated: $\Delta=0.21$. The frontal layer in the rod-impact $\mathrm{SiC}$ specimen is subjected to a uni-axial strain state $\left(\varepsilon_{22}=\varepsilon_{33}=0\right)$, 

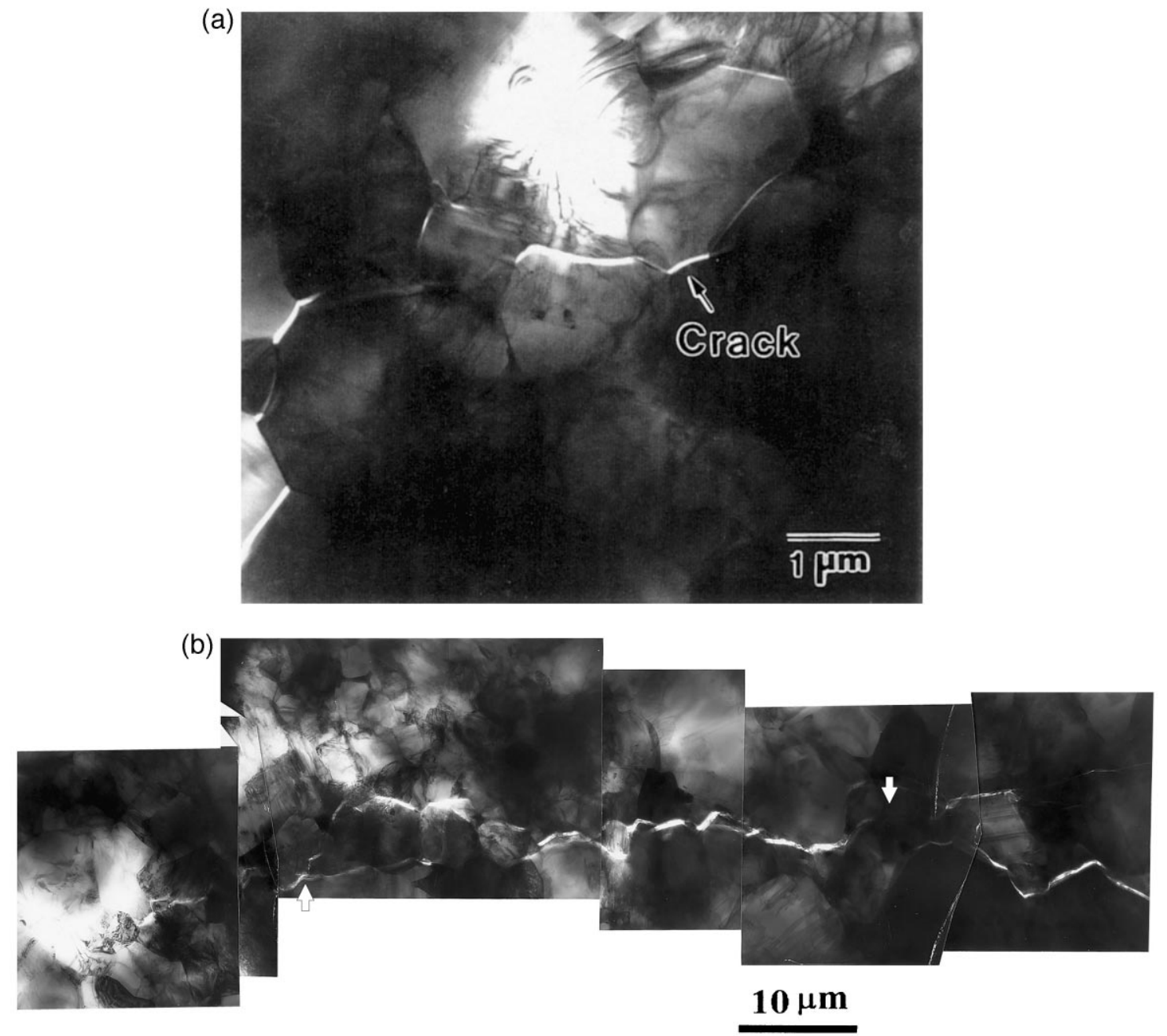

Fig. 11. (a) Detail of intergranular microcrack. (b) Montage of TEM micrographs showing trajectory of crack-Area 2 in Fig. 10.

which is the characteristic of shock waves:

$$
\begin{gathered}
\varepsilon_{11}=\frac{1}{E}\left[\sigma_{11}-v\left(\sigma_{22}+\sigma_{33}\right)\right] \\
\varepsilon_{22}=\frac{1}{E}\left[\sigma_{22}-v\left(\sigma_{11}+\sigma_{33}\right)\right]=0 \\
\varepsilon_{33}=\frac{1}{E}\left[\sigma_{33}-v\left(\sigma_{11}+\sigma_{22}\right)\right]=0
\end{gathered}
$$

where $E$ is the Young's modulus, and $v$ is the Poisson's ratio. Because of the geometry symmetry $\left(\sigma_{22}=\sigma_{33} \neq 0\right)$, the following expression can be obtained:

$$
\frac{\sigma_{22}}{\sigma_{11}}=\frac{v}{1-v}
$$

Poisson's ratio for $\mathrm{SiC}$ is about 0.17 , and the lateral confinement can therefore be obtained: $\sigma_{22} /$ $\sigma_{11}=0.20$. As shown in Fig. 13(b), the frontal layer falls into the region for ductile failure mode. In accordance with the model proposed by Horii and Nemat-Nasser [73] suggesting the presence of the plastic zones, the TEM analysis clearly shows the presence of dislocations. The high lateral confinement and its intrinsic high ductility parameter allow the material to deform inelastically; as a result, the frontal layer does not exhibit significant comminution during impact. However, the rod impact generates spherical stress waves, and the uni-axial strain condition vanishes rapidly, resulting in a dramatic decrease in the lateral confinement $\left(\sigma_{22} / \sigma_{11}\right)$ through the surrounding material. Away from the interface, shear stresses become dominant, and a localized comminution zone (Mescall zone) develops.

\section{CONCLUSIONS}

1. Two hot-pressed $\mathrm{SiC}$, representing two major families of $\mathrm{SiC}$, were dynamically deformed by split Hopkinson-Kolsky bar to study the damage 
(a)

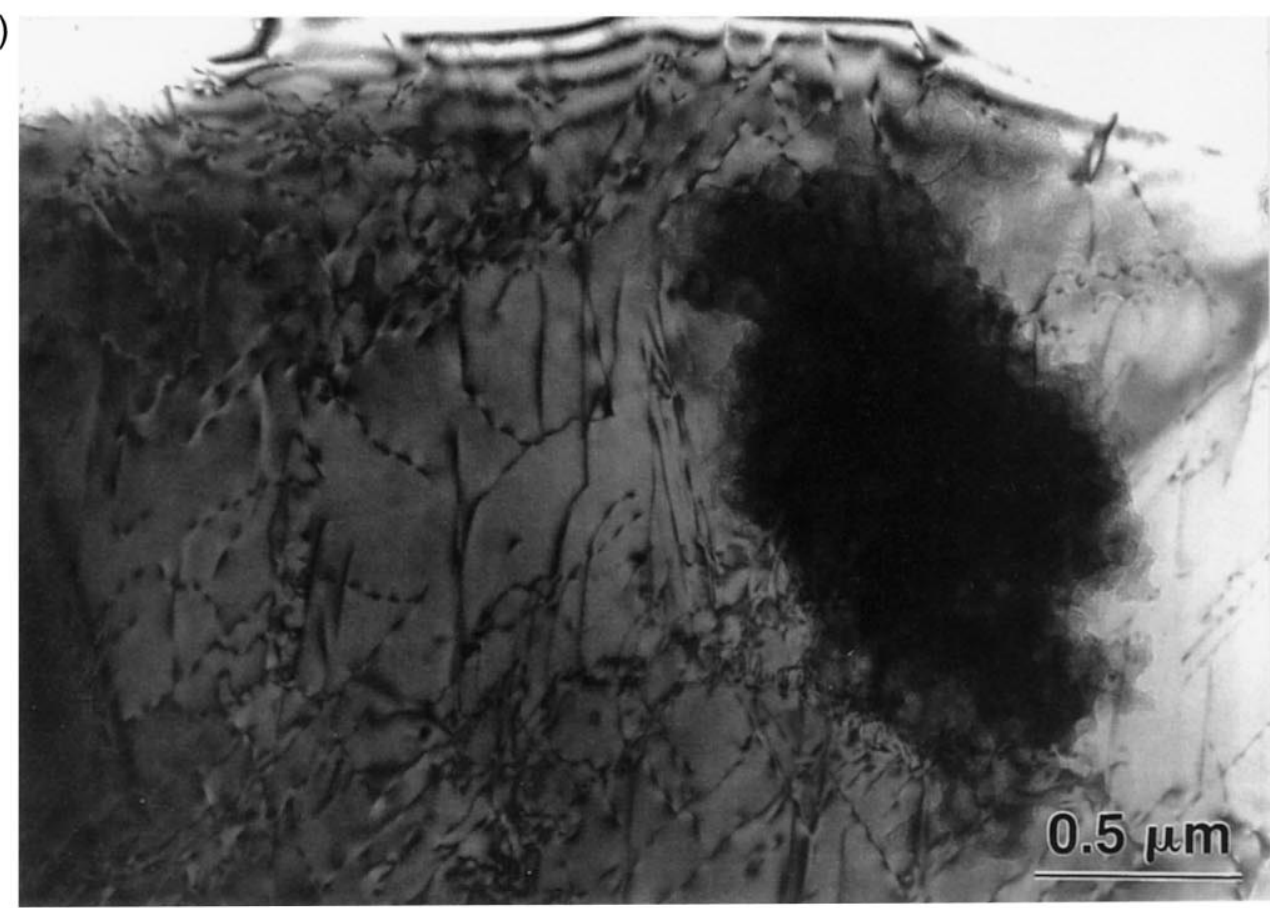

(b)

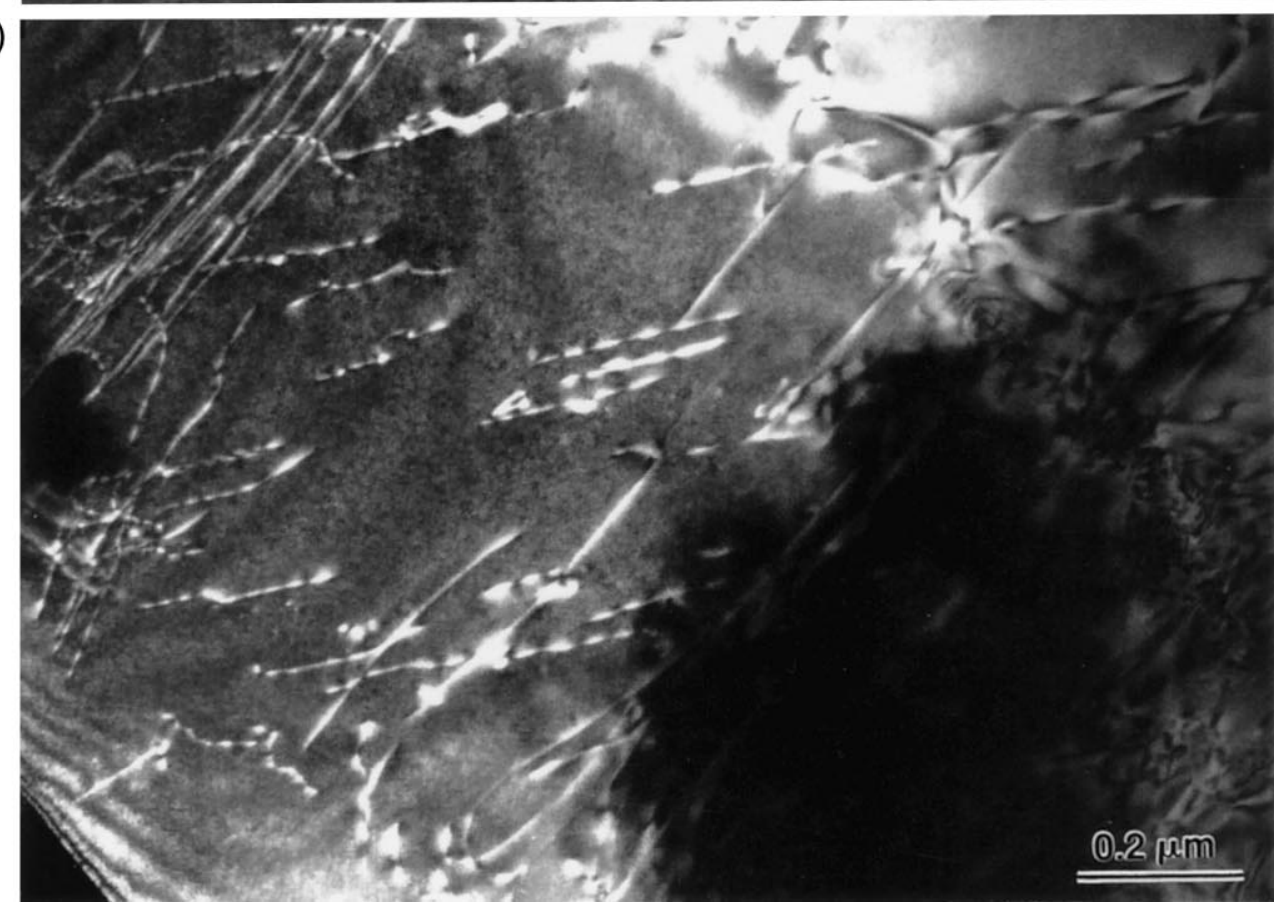

Fig. 12. Dislocations at immediate vicinity $(10 \mu \mathrm{m})$ from impact interface (Area 1 in Fig. 10): (a) bright field; (b) dark field.

evolution. The Al-doped SiC-II had a higher strength than the B-doped SiC-I, because of the absence of strength-limiting processing flaws. SiC-I failed by transgranular fracture, whereas, the SiC-II failed by intergranular fracture. The fracture mode was independent of the strain rate, and the SiC-exhibiting intergranular fracture had a higher fracture toughness, because of crack deflection toughening.

2. The fragment size was influenced by the fracture toughness, as proposed by Grady [24]. A modification of the Grady analysis, with additional terms for internal damage and plastic deformation, is proposed.

3. Polytype transformation was observed during the dynamic deformation. $6 \mathrm{H}-\mathrm{SiC}$ was the major 


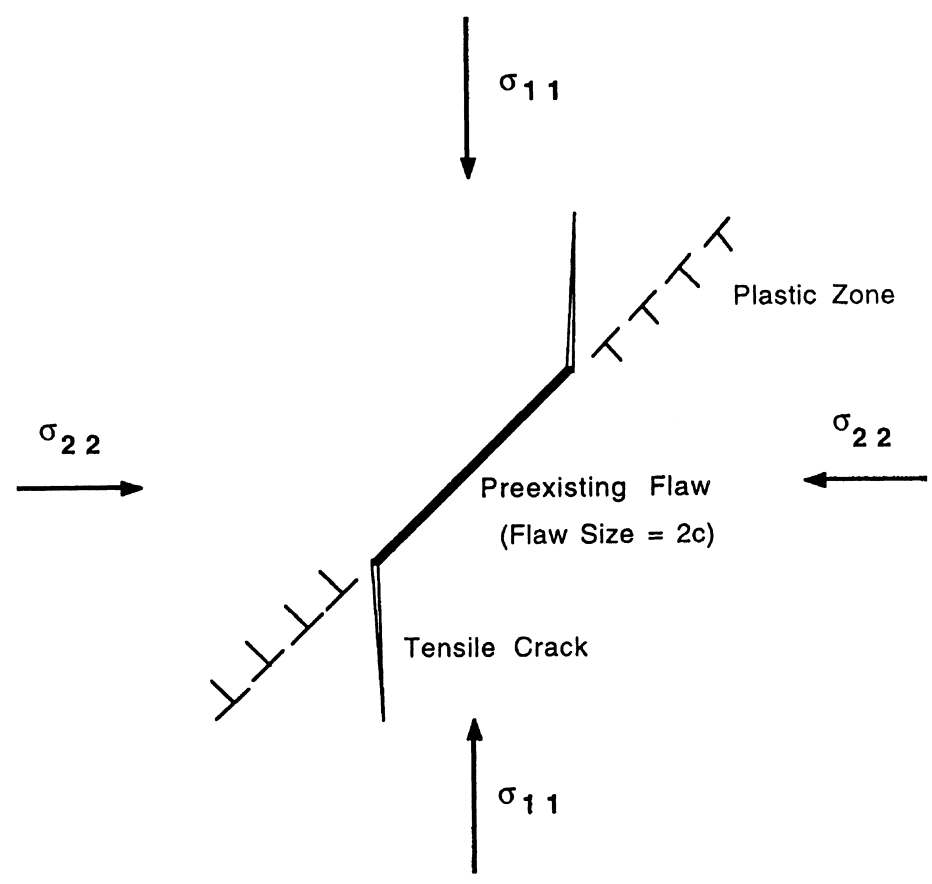

(a)

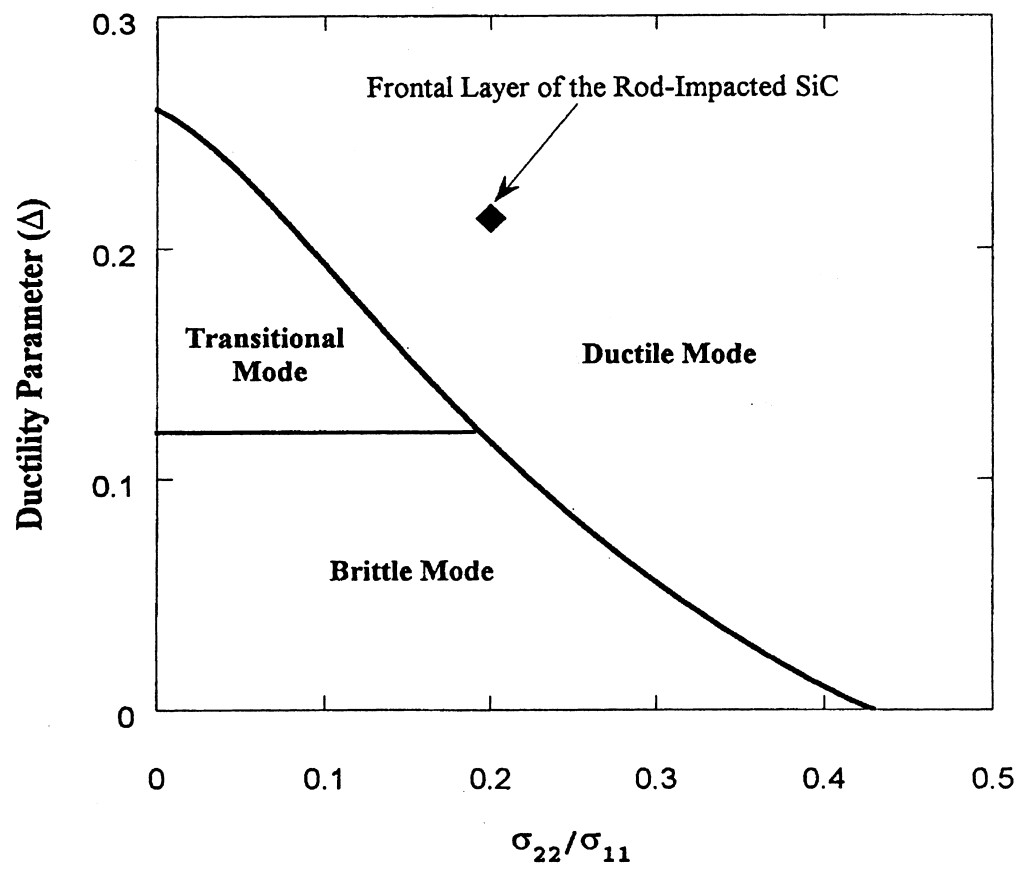

(b)

Fig. 13. Compressive failure of brittle materials (adapted from Nemat-Nasser and Hori [74]): (a) plastic zone around the crack tip; (b) brittle-ductile diagram. 
polytype in both $\mathrm{SiC}$. As the impact stress exceeded $4.5 \mathrm{GPa}$, the $6 \mathrm{H}-\mathrm{SiC}$ content increased.

4. Stacking faults and dislocations were the two major microstructural defects. Dislocations were not active in $\mathrm{SiC}$-I, but generation and pile-up of dislocations were observed in the Al-doped $\mathrm{SiC}$ (SiC-II) during dynamic deformation.

5. Five failure initiation mechanisms are discussed: (a) grain-boundary debonds and (b) voids, (c) Zener-Stroh cracks due to dislocation pile-ups, (d) stress concentrations at grain boundaries produced by stacking faults and polytypes, (e) dilatant cracks due to elastic anisotropy. Finite element calculations show that anisotropy effects can generate local tensile stresses of $220 \mathrm{MPa}$ at an applied compressive stress of $-5 \mathrm{GPa}$.

6. The frontal layer in the rod-impacted $\mathrm{SiC}$ in interface defeat conditions was characterized. Extensive dislocations were observed at the impact surface, which was shocked at a pressure exceeding its Hugoniot elastic limit. We proposed that it does not exhibit brittle comminution, because of high lateral confinement, generated by the surrounding material. This microplastic deformation regime is interpreted in terms of a "ductility parameter" $\Delta$.

Acknowledgements - This research is supported by the US Army Research Office through AASERT (DAAH04-94-G0314) and MURI (DAAH04-96-1-0376) programs, Institute for Mechanics and Materials, and Cercom Inc (Vista, CA). The authors wish to acknowledge E. J. Rapacki and G. Hauver at ARL for providing the invaluable rod-impacted specimen, J. B. Isaacs (CEAM/UCSD) for training and assistance in Hopkinson-Kolsky bar experiments, A. J. Strutt (UCSD) for help in TEM, Y. Liu (UCSD) for the assistance in multi-regression, C.-Y. Song at NCEM for TEM sample preparation for the rodimpacted specimen, V. Lubarda for discussions on crystal anisotropy, and E. Strutt at UCSD for editing.

\section{REFERENCES}

1. Griffith, A. A., in Proc. 1st Int. Congress for Appl. Mech., 1924, p. 55.

2. McClintock, F. A. and Walsh, J. B., in Proc. 4th US Congress for Appl. Mech., 1962, p. 1015.

3. Castaing, J., Cadoz, J. and Kirby, S. H., J. Am Ceram. Soc., 1981, 64, 504.

4. Pletka, B. J., Heuer, A. H. and Mitchell, T. E., Acta metall., 1977, 25, 25.

5. Pletka, B. J., Mitchell, T. E. and Heuer, A. H., Acta metall., 1982, 30, 147.

6. Lagerlof, K. P. D., Pletka, B. J., Mitchell, T. E. and Heuer, A. H., Radiat. Effects, 1983, 74, 87.

7. Lankford, J. J., Mater. Sci., 1981, 16, 1567.

8. Hoke, D. A., Gray, G. T. and Meyers, M. A., unpublished results, 1998.

9. Chen, W. and Ravichandran, G., J. Am. Ceram. Soc. 1996, 79, 579.

10. Leme, Louro L. H. and Meyers, M. A., Mater. Sci. Engng, 1989, 24, 2516.

11. Espinosa, H. D., Micromechanics of the dynamic re- sponse of ceramics and ceramic composites, Ph.D. dissertation, Brown University, 1991.

12. Espinosa, H. D., Raiser, G., Clifton, R. J. and Ortiz, M., J. Hard Mater., 1992, 3, 285.

13. Komeya, K. and Matsui, M., Structure and Properties of Ceramics, Materials Science and Technology, Vol. 11, VCH, Weinheim, 1994, p. 517.

14. Prochazka, S., General Electric Corp. Technical report No. 81CRD314, Schenectady, 1981.

15. Telle, R., Structure and Properties of Ceramics, Materials Science and Technology, Vol. 11, VCH, Weinheim, 1994, p. 173.

16. Srinivasan, M., Structural Ceramics, Treatise on Materials Science and Technology, 1989, 29, 99.

17. Munz, D. G., Shannon, J. L. and Bubsey, R. T., Int J. Fracture, 1980, 16, R137.

18. Jones, R. H., Schilling, C. H. and Schoenlein, L. H., Materials Science Forum, 1989, 46, 277.

19. Ravichandran, G. and Subhash, G., J. Am. Ceram. Soc., 1994, 77, 263.

20. Nemat-Nasser, S., Isaacs, J. B. and Starrett, J. E., Proc. R. Soc. Lond. A, 1991, 435, 371.

21. Sharma, V., Damage evolution in hot-pressed silicon nitride under repeated dynamica and quasi-static compression loading, Ph.D. dissertation, UCSD, 1994.

22. Hauver, G. E., Netherwood, P. H., Benck, R. F. and Kecskes, L. J., in Proc. 13th Army Symp. Solid Mech., 1993 , p. 23

23. Hauver, G. E., Netherwood, P. H., Benck, R. F. and Kecskes, L. J., in Proc. 19th Army Science Con., 1994, p. 1.

24. Rapacki, E. J., Hauver, G. E., Netherwood, P. H. and Benck, R., Ceramics for armors-a materials system perspective, in 19th Ann. TARDEC Ground Vehicle Surv. Symp, March, Monterrey, CA, 1996.

25. Espinosa, H. D., Brar, N. S., Yuan, G., Xu, Y. and Arrieta, V., Int. J. Solids Struct., 1999, 4, 1.

26. Rice, R. W., Fractography of Glasses and Ceramics, Advances in Ceramics, Vol. 22, The American Ceramic Society, Westerville, OH, 1986, pp. 3-56.

27. Rice, R. W., in Fractography of Ceramic and Metal Failure, , ASTM STP 827. American Society for Testing and Materials, Philadelphia, PA, 1984, pp. 5103

28. Lankford, J., Fracture Mechanics of Ceramics, Vol. 5, Plenum Press, New York, 1983, p. 625.

29. Lankford, J., J. Am. Ceram. Soc., 1981, 64, C-33.

30. Nemat, Nasser S. and Deng, H., Acta metall. mater, 1994, 42, 1013

31. Ravichandran, G. and Subhash, G., Int. J. Solids Struct., 1994, 32, 2627.

32. Subhash, G. and Ravichandran, G., Mechanical behavior of hot pressed aluminum nitride under uniaxial compression, Graduate Aeronautical Labs, California Inst. of Technology, SM Report 93-7.

33. Grady, D. E., J. appl. Phys., 1982, 53, 322.

34. Aimone, C. T., Meyers, M. A. and Mojtabai, N., in Rock Mechanics in Productivity and Production, ed. C. Dowding and M. M. Singh. AIME, 1984, p. 979.

35. Meyers, M. A., in Mechanics and Materials, ed. M. A. Meyers, R. W. Armstrong and H. O. K. Kirchner. Wiley, New York, 1999, p. 489.

36. Brockenbough, J. R., Suresh, S. and Duffy, J., Phil. Mag., 1988, 58, 619.

37. Suresh, S., Nakamura, T., Yeshurun, Y., Yang, K.-H and Duffy, J., J. Am. Ceram. Soc., 1990, 73, 2457.

38. Cagnoux, J. and Longy, F., J. Phys., 1988, C3, 3.

39. Yeshurun, Y., Brandon, D. G., Venkert, A. and Rosenberg, Z., J. Phys., 1988, C3, 11.

40. Louro, L. H. L., Stress-wave induced damage in alumina-based ceramics, Ph.D. thesis, New Mexico Institute of Mining and Technology, Socorro, NM, 1990. 
41. Ashby, M. F. and Hallam, S. D., Acta metall., 1986, 34, 497.

42. Samms, C. G. and Ashby, M. F., Acta metall., 1986, 34, 511 .

43. Dobson, M. M., Silicon Carbide Alloy. The Parthenon Press, 1986.

44. Pandey, D. and Krishna, P., in Silicon Carbide-1973. University of South Carolina Press, SC, 1974, p. 198.

45. Tanaka, H. and Iyi, N., J. Ceram. Soc. Jpn. Int. Ed, 1993, 101, 1281

46. Pujar, V. V. and Cawley, J. D., J. Am. Ceram. Soc., $1995,78,774$.

47. Tateyama, H., Sutoh, N. and Murakawa, N., J. Ceram. Soc. Jpn. Int. Ed., 1988, 96, 985.

48. Yang, J. W. and Pirouz, P., J. Mater. Res., 1993, 8, 2902.

49. Song, S. G., Vaidya, R. U., Zurek, A. K. and Gray, G. T., Metal. Mater. Trans. A, 1996, 27A, 459.

50. Stevens, R., J. Mater. Sci., 1972, 7, 517.

51. Maeda, K., Suzuki, K., Fujita, S., Ichihara, M. and Hyodo, S., Phil. Mag. A, 1988, 57, 573.

52. Weertman, J. and Weertman, J. R., in Elementary Dislocation Theory. Oxford University Press, New York, 1992, p. 98.

53. Amelinckx, S., Strumane, G. and Webb, W., J. appl. Phys., 1960, 31, 1359.

54. Pilyankevich, A. N. and Britun, V. F., Phys. Stat. Sol., 1984, 82, 449.

55. Stevens, R., J. Mater. Sci., 1971, 6, 324.

56. Seo, W. S., Pai, C. H., Kunihito, K. and Yanagida, H., J. Ceram. Soc. Jpn. Int. Ed., 1992, 100, 240.

57. Dummer, T., LaSalvia, J. C., Ravichandran, G. and Meyers, M. A., Acta mater., 1998, 46, 6267.

58. Zener, C., in Fracturing of Metals. American Society for Metals, Metal Park, OH, 1948, p. 3.

59. Stroh, A. N., Adv. Phys., 1957, 6, 418.

60. Tapponier, P. and Brace, W. F., Int. J. Rock Mech Min. Sci. Geomech. Abstr., 1976, 13, 103.

61. Ghahremani, F., Tvergaard and Hutchinson, J., J. Am. Ceram. Soc., 1990, 73, 1548.

62. Ghahremani, F. and Shih, C. F., J. Appl. Mech., 1992, 59, 61.

63. Espinosa, H. D., Dwivedi, S., Zavattieri, P. D. and Yuan, G., Int. J. Solid Struct., 1998, 35, 2975.

64. Shockey, D., Marchand, A. H., Skaggs, S. R., Cort, G. E., Birckett, M. W. and Parker, R., Int. J. Impact Engng, 1990, 9, 263.

65. Viechnicki, D. J., Slavin, M. J. and Kliman, M. I., Ceram. Bull., 1991, 70, 1035.

66. Meyers, M. A., Dynamic Behavior of Materials. Wiley, New York, 1994.

67. Shih, C. J., Meyers, M. A. and Nesterenko, V. F., Acta mater., 1998, 46, 4037.

68. Hauver, G. E., private communication, 1995.

69. Meyers, M. A. and Murr, L. E., in Shock Waves and High-Strain-Rate Phenomena in Metals, Concepts and Applications. Plenum Press, New York, 1981, p. 1045.

70. Steinberg, D. J., J. Phys. IV, 1994, C8, 183.

71. Grady, D. E., Mech. Mater., 1998, 29, 181.

72. Espinosa, H. D., Int. J. Solids Struct., 1995, 32, 3105.

73. Horii, H. and Nemat-Nasser, S., Phil. Trans. Roy. Soc. Lond., 1986, 319, 337.

74. Nemat-Nasser, S. and Hori, M., in Micromechanics: Overall Properties of Heterogeneous Materials. NorthHolland, Amsterdam, 1993, pp. 180-185.

75. Hofmann, M., Zywietz, A., Karch, K. and Bechstedt, F., Phys. Rev. B, 1994, 50, 13401.

76. Nye, J. F., in Physical Properties of Crystals. Oxford University Press, London, 1969, p. 143.

\section{APPENDIX A}

\section{A1. Elastic anisotropy}

$\mathrm{SiC}$ has various polytypes, and their elastic constants are different. The XRD results indicated that $6 \mathrm{H}-\mathrm{SiC}$ is the major polytype in both $\mathrm{SiC}-\mathrm{I}$ and $\mathrm{SiC}$-II; the elastic constants (stiffness tensor $[C]$ ) for $6 \mathrm{H}-\mathrm{SiC}$ are reported as follows [75]:

$$
[C]=\left[\begin{array}{llllll}
498 & 186 & 176 & 0 & 0 & 0 \\
186 & 498 & 176 & 0 & 0 & 0 \\
176 & 176 & 567 & 0 & 0 & 0 \\
0 & 0 & 0 & 141 & 0 & 0 \\
0 & 0 & 0 & 0 & 141 & 0 \\
0 & 0 & 0 & 0 & 0 & 156
\end{array}\right](\mathrm{GPa}) .
$$

The effective Young's modulus along an arbitrary $\tilde{n}$ direction can be calculated through the corresponding strain $\left(\varepsilon_{n}\right)$ and the stress $\left(\sigma_{n}\right)$ :

$$
\frac{1}{E_{\mathrm{n}}}=\frac{\varepsilon_{\mathrm{n}}}{\sigma_{\mathrm{n}}}
$$

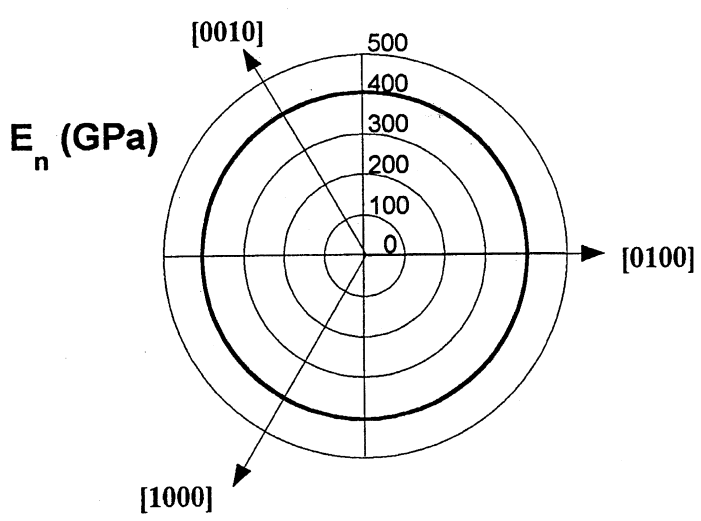

(a)

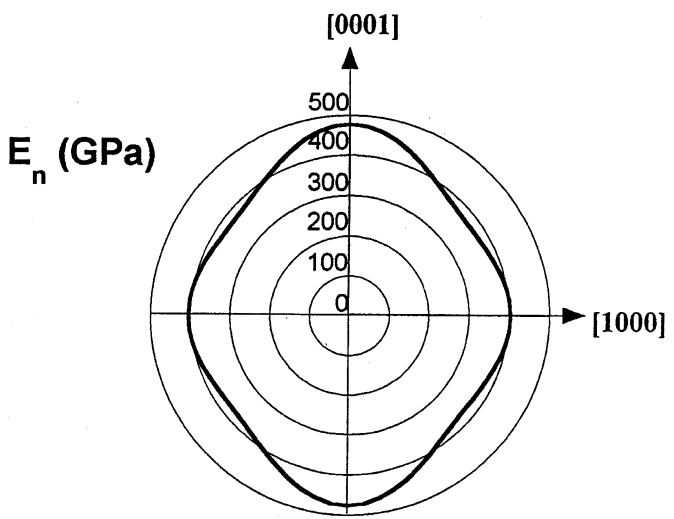

(b)

Fig. A1. Effective Young's modulus. (a) On the basal plane, (b) on the prismatic plane. 


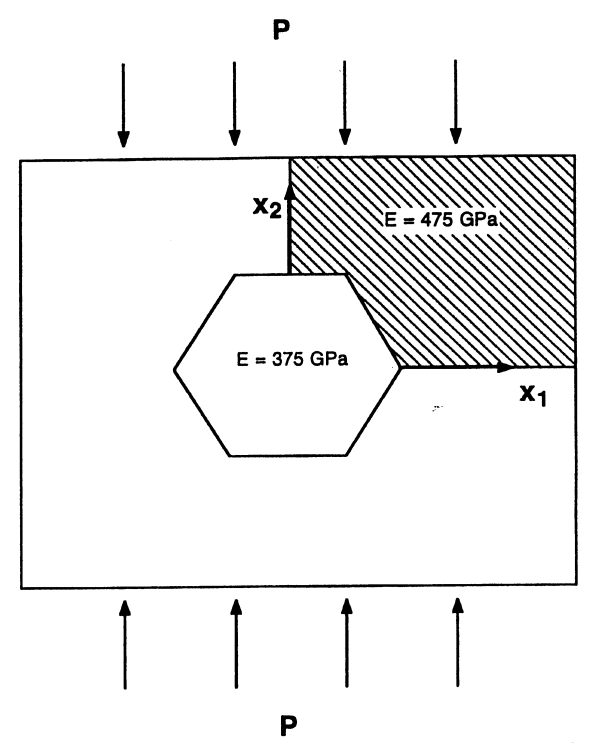

(a)

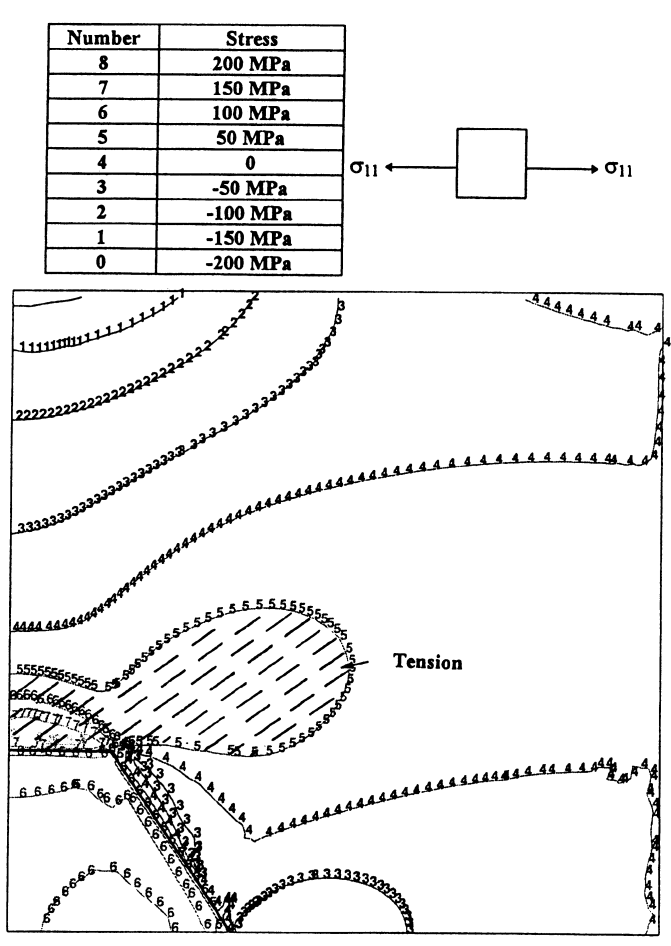

(b)
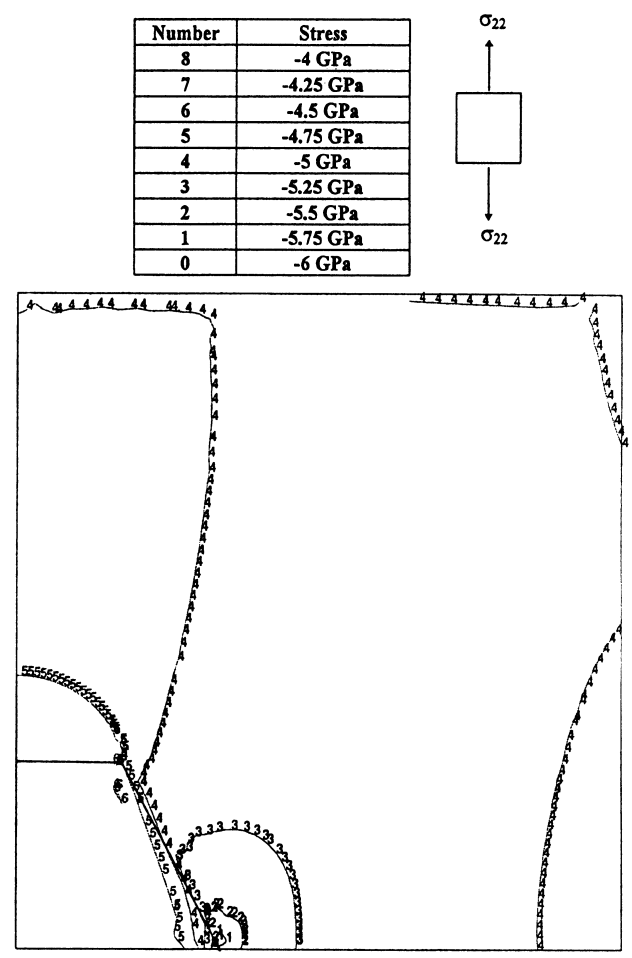

(c)

Fig. A2. Effect of anisotropy: (a) schematic diagram for finite element analysis; (b) isostress contours of $\sigma_{11}$; (c) isostress contours of $\sigma_{22}$. (Positive stresses are tensile; negative stress are compressive.) 
For hexagonal crystals, the effective Young's modulus is isotropic on the basal planes and it is given by $1 / E_{\mathrm{n}}=S_{11}$. The effective Young's modulus on the prismatic planes can be expressed as [76]:

$$
\begin{aligned}
& \frac{1}{E_{\mathrm{n}}}=S_{11} \sin ^{4} \theta+S_{33} \cos ^{4} \\
& \quad \theta+\left(S_{44}+2 S_{13}\right) \sin ^{2} \theta \cos ^{2} \theta
\end{aligned}
$$

where $S_{i j}$ is the compliance tensor $\left([S]=[C]^{-1}\right.$, and $S_{11}, S_{33}, S_{44}$, and $S_{13}$ are $0.00174,0.00210,0.00709$, and $-0.000540 \mathrm{GPa}^{-1}$, respectively), and $\theta$ is the angle between the $\tilde{n}$ direction and the crystallographic $z$-axis (the [0001] direction). The calculated values for $E_{\mathrm{n}}$ on the basal and prismatic planes are graphically represented in Fig. A1. On prismatic planes, the stiffness varies from 375 to $475 \mathrm{GPa}$. In order to quantitatively evaluate the stresses induced from compressive tractions by a stiffness mismatch, a two-dimensional finite element calculation, containing a soft grain $(E=375 \mathrm{GPa})$ surrounded by a stiff matrix ( $E=475 \mathrm{GPa})$, was used, as shown in Fig. 18(a). For simplicity, the soft grain and the stiff matrix were assumed to deform isotropically, with the same Poisson's ratio $(v=0.17)$. A plane stress condition was used in the calculation. A compressive load $(\mathrm{P}=5 \mathrm{GPa}$, representing the failure strength of $\mathrm{SiC}$ ) was applied. The following two boundary conditions were used:

$$
\begin{aligned}
\Delta x_{1} & =0 \quad \text { at } x_{1}=0 \text { and } \Delta x_{2}=0 \text { at } \\
x_{2} & =0 .
\end{aligned}
$$

The loading direction is parallel to the $x_{2}$ axis, and the calculated stresses $\left(\sigma_{11}\right.$ and $\left.\sigma_{22}\right)$ are shown in Figs A2(b) and A2(c), respectively. Stress $\sigma_{22}$ is tensile and equal to $-5 \mathrm{GPa}$ in regions away from the central grain, as expected. On the other hand, $\sigma_{11}$, perpendicular to the external tractions, shows both tensile and compressive stresses. Induced tensile stresses in $\sigma_{x x}$ can be identified around the soft grain, and the maximum tensile stress $(220 \mathrm{MPa})$ is in the stiff matrix adjacent to the interface between the two grains. The calculated value of the tensile stress $(220 \mathrm{MPa})$ is on the same order of magnitude of the flexural strength of $\mathrm{SiC}(380-540 \mathrm{GPa})$. The tensile stress region in the stiff matrix is marked by hatching in Fig. A2(a), and the compliant grain is entirely under tension. This tensile stress, perpendicular to the compressive loading direction, can nucleate a crack from a local microstructural defect, such as a stacking fault impinging on the grain boundary, a pore, a grain boundary phase, or a grain-boundary ledge. It may cause splitting of the grains, leading to the transgranular fracture. 